\title{
Fernando Rosales (1754-1830), el último Maestro Mayor tardobarroco del Arzobispado de Sevilla
}

\author{
Fernando Rosales (1754-1830), the last Baroque \\ Major Master of the Archbishopric of Seville
}

\author{
José Manuel Higuera Meléndez \\ Universidad de Sevilla \\ josemhiguera@gmail.com \\ ID ORCID 0000-0002-2911-1009
}

\begin{abstract}
Resumen: El arquitecto sevillano Fernando Rosales, cuya vida profesional se desarrolló a caballo entre los siglos xvIII y XIX, fue uno de los más activos maestros mayores de obras de la Iglesia de Sevilla. De carácter afable, tuvo sin embargo algunos sonoros desencuentros con el arquitecto José Echamorro, que aquí se exponen. $Y$ al igual que ocurrió a sus compañeros en el cargo, la Real Academia de San Fernando rechazó sus proyectos enviados a dicha institución. Eclipsada por la de Antonio de Figueroa y José Álvarez, el estudio monográfico de su obra está aún por abordar. Este trabajo pretende contribuir a su conocimiento, mediante la aportación de numerosas noticias inéditas, tanto biográficas como profesionales, algunas de las cuales subsanan persistentes errores historiográficos, contextualizándolas entre sus más conocidas realizaciones.
\end{abstract}

Palabras clave: Fernando Rosales, Arquitectura barroca sevillana, José Echamorro, Real Escuela de las Tres Nobles Artes.

\begin{abstract}
The Sevillian Architect Fernando Rosales, who developed his professional life between the 18th -19th centuries, was one of the most active master builders to the Church in Sevilla. Holder of an affable personality, he but had some loud disagreements with Architect José Echamorro that are to see daylight here and now. Same as his colleagues, the San Fernando Royal Academy rejected all the projects he sent over that venerable institution. His work and chores, overshadowed by Antonio's de Figueroa and José's Álvarez, are in need of a deep monography yet to see light. These notes try to enrich his best known achievements contributing with large unpublished biographical, professional true news, revoking persistent historiographical errors.
\end{abstract}

Keywords: Fernando Rosales, Sevillian Baroque Architecture, José Echamorro, Royal School of the Three Noble Arts. 
Fernando Rosales y Ramos (1754-1830), maestro mayor de obras de la Iglesia desde 1784, desarrolló más de la mitad de su vida laboral en el siglo XIX, aunque las circunstancias sociales, económicas y profesionales de la época propiciaron que llevase a cabo la mayoría de sus realizaciones a las órdenes del arzobispado hispalense antes del cambio de siglo.

Su nombre va siempre unido a los de Antonio de Figueroa y José Álvarez, con los cuales coincidió en el cargo, como representantes de la "escuela de arquitectos tardobarrocos sevillanos", si bien los dos primeros, por pertenecer a la generación anterior, acapararon la mayor parte de las obras (y, sobre todo, la de más entidad y lucimiento) que la archidiócesis acometió para reconstruir los templos afectados por el terremoto de Lisboa (1755). Consecuentemente, la historiografía del arte ha otorgado un papel secundario a Fernando Rosales. No obstante, es de justicia poner en valor su obra; primero porque diversas realizaciones de los dos veteranos maestros iban a ser después ampliadas, reformadas o reedificadas por él, como se verá; y en segundo lugar, por la influencia que aquella pudo ejercer en la evolución de la arquitectura sevillana mediante la definitiva superación de la estética del barroco.

\section{EL PANORAMA PROFESIONAL EN LA ARCHIDIÓCESIS DE SEVILLA A FINALES DEL XVIII: LA PRESIÓN DE LA ACADEMIA Y SU INTRANSIGENCIA CON LOS MAESTROS HISPALENSES}

Durante el ejercicio de su cargo al frente de la maestría mayor de la diócesis hispalense, Fernando Rosales abrazó los postulados artísticos academicistas, como destacado alumno que fue de la Real Escuela de las Tres Nobles Artes de Sevilla. Sin embargo, su obra religiosa mantendría los esquemas compositivos y modelos tipológicos del barroco diocesano gracias, entre otras razones, a su "instrucción" con Antonio de Figueroa (1733-1793), "el último arquitecto barroco sevillano", quien decía de aquel "ser sus prollectos de toda aprovacion por lo afable y buen modo del dicho Rosales". 1 Informe de Figueroa de 21.Jul.1788, sobre la construcción de la iglesia ecijana de
Santa Cruz. AGAS, Justicia, Pleitos ordinarios, Leg. 10319, F. 351r-357v. 
De los maestros mayores diocesanos de referencia de la segunda mitad del setecientos, ${ }^{2}$ Rosales es el único que vivirá y trabajará hasta bien entrado el siglo XIX, haciendo evolucionar su obra incluso hacia posiciones historicistas basadas en el revivalismo de estilos pasados, como se pone de manifiesto en su propuesta neogótica de 1827 para finalizar la portada de la Asunción de la catedral de Sevilla. ${ }^{3}$ Y del mismo modo que sucedía con José Álvarez (1723-1800), aparte de noticias muy específicas dadas a conocer en diversas publicaciones generales y artículos, hasta fechas recientes no se habían producido aproximaciones de relevancia al conjunto de su vida y obra desde la investigación del profesor Sancho Corbacho. ${ }^{4}$

Por otra parte, Rosales fue nombrado maestro mayor de obras del arzobispado de Sevilla casi tres décadas después de acontecido el terremoto de Lisboa, que había provocado una auténtica fiebre renovadora de los templos de la diócesis. Así pues, la mayoría de los de nueva planta ya habían sido proyectados por Silva, Ambrosio y Antonio de Figueroa y Álvarez, encontrándose muchos de ellos aún en ejecución cuando el nuevo maestro mayor accedió a su cargo; por lo cual le correspondió principalmente la supervisión y reforma de buena parte de estas obras, en particular las que Antonio de Figueroa dejó inconclusas a su fallecimiento.

La prematura muerte del nieto de Leonardo de Figueroa, además de suponer para la diócesis la pérdida de su más prolífico maestro mayor, representó en la práctica el final del espíritu barroco que había imperado durante casi todo el siglo XVIII en la Baja Andalucía,

2 Pedro de Silva, Ambrosio y Antonio de Figueroa, José Álvarez y el propio Rosales.

3 Cf. Teodoro Falcón Marquéz, La catedral de Sevilla, estudio arquitectónico, Sevilla, Diputación Provincial de Sevilla, 1980, 97 y 102. El plano de dicha portada allí publicado, dibujado por Rosales, se ha perdido. También cf. Francisco Ollero LOBATO, "La aparición de los estilos históricos en la Sevilla decimonónica", en Teresa SAURet (ed.), Usos, costumbres y esencias territoriales, Málaga, UMA, 2010, 158-167.

4 Cf. Antonio Sancho Corbacho, Arquitectura barroca sevillana del siglo XVIII, Madrid, CSIC, 1952, reed. 1984, 263. Sobre Fernando Rosales, cf. Teodoro Falcón, Documentos para el estudio de la arquitectura onubense, Huelva, Diputación de Huelva, 1977; Teodoro Falcón, Iglesias de la Sierra de Cádiz, Cádiz, Caja de Ahorros de Cádiz y Monte de Piedad, 1983; Francisco Ollero Lobato, Cultura artística y arquitectura en la Sevilla de la Ilustración (1775-1808), Sevilla, Caja San Fernando, 2004, 383-403. Y en relación con José Álvarez, cf. José Manuel Higuera Meléndez, “José Álvarez (1723-1800), maestro mayor de obras del arzobispado de Sevilla", Isidorianum, 25/50 (2016) 353-384: https://doi.org/10.46543/ ISID.1625.1036. 
en un esfuerzo inútil por soslayar los vientos de cambio artísticos y profesionales. De esta manera, coincidiendo también con el final del Antiguo Régimen, se produciría la ineludible catarsis de la tradición vernácula constructiva, que recaía desde hacía siglos en el hasta entonces intocable estamento gremial. Sin embargo, la resistencia de las viejas instituciones era tal que, a pesar de la presión que desde hacía décadas venía ejerciendo la Real Academia de San Fernando, en ciudades como Sevilla, los maestros de obras formados aún en la tradición gremial ${ }^{5}$ continuarían desarrollando su trabajo durante las primeras décadas del XIX. ${ }^{6}$

El aprendizaje y la preparación de estos maestros se basaba en la transmisión de atávicos conocimientos de tipo práctico y empírico $\mathrm{y}$, todo lo más, en el manejo de algunos manuales que circulaban habitualmente, como el de fray Lorenzo de San Nicolás. Aquellos que aspiraban al nombramiento de los cargos más apetecidos, como eran los de maestro mayor de la diócesis, del cabildo catedralicio o de la ciudad, tenían que suplir las deficiencias teóricas de la enseñanza gremial "mediante lecturas de tratados teóricos y libros técnicos sobre arquitectura, ingeniería y mecánica, así como mediante el manejo de dibujos y láminas de obras extranjeras" 7 pues, por lo general, los maestros barrocos españoles del siglo XVIII nunca viajaron a Europa.

Si bien desde 1761 se venía reclamando por el estamento académico que todas las ciudades e instituciones con maestros de obras a su cargo nombrasen únicamente a individuos aprobados en la Academia de Madrid, el arzobispado de Sevilla siguió nombrando maestros mayores de obras que no pertenecían a la Academia hasta entrado el siglo XIX. Así, en las décadas finales del XVIII accederían oficialmente al cargo Fernando Rosales (1784), Santiago de la Llosa (1794) y, ocupando la plaza de José Álvarez, Juan José Rosales (1799),

5 Entre ellos se encontraban los maestros Fernando Rosales y José Echamorro, quienes a pesar de haber realizado estudios académicos o formar parte incluso de la Academia local, provenían de la tradición gremial heredada de sus padres.

6 Hasta 1826 no llegaría a Sevilla ningún arquitecto titulado por la Real Academia de San Fernando. El primero fue el madrileño Melchor Cano, traído a la ciudad por el ilustrado Asistente José Manuel de Arjona. Cf. José Manuel SuÁrez GARMEndia, Arquitectura y urbanismo en la Sevilla del siglo XIX, Sevilla, Diputación Provincial de Sevilla, 1986, 33.

7 Alfonso Rodríguez G. DE CEBAllos, El siglo XVIII, entre tradición y academia (Introducción al arte español), Sílex, Madrid, 1992, 37. 
hermano de Fernando. ${ }^{8}$ Los nuevos maestros mayores practicarían un barroco tardío de tipo clasicista en sus obras para la Iglesia de Sevilla, arquitectura hacia la que también evolucionó la obra diocesana de José Álvarez y de Antonio de Figueroa desde postulados más cercanos al denominado "barroco castizo". ${ }^{\text {? }}$

La Comisión de Arquitectura de la Real Academia, puesta en marcha el 22 de marzo de 1786, significó el establecimiento definitivo de un nuevo orden jerárquico y jurisdiccional en el terreno arquitectónico que supuso una molesta rémora para la finalización de las obras en marcha y para la viabilidad de los nuevos proyectos. Pero, sin duda, el golpe más duro fue el moral recibido por sus alarifes.

En efecto, el aggiomamento de los maestros mayores del arzobispado de Sevilla no evitó el degradante trato recibido por parte de la Real Academia"en aras del buen gusto".${ }^{10} \mathrm{Si}$ los cinco proyectos de Antonio de Figueroa enviados a Madrid y evaluados por la Academia ${ }^{11}$ fueron tildados de"malos por falta de disposicion, buena forma y economia", los dictámenes relativos a los proyectos de

8 La Real Orden de 1787 también declaraba "nulos y de ningún valor ni efecto los títulos de arquitectos y maestros de obras o de albañilería que los Prelados, Cabildos, Ayuntamientos y Gremios hayan expedido", prohibiéndose los exámenes del gremio por otra Real Orden de 5.Ene.1801. Sin embargo, la situación se prolongaría hasta agosto de 1816, en que a los maestros mayores de la diócesis Santiago de la Llosa y Juan José Rosales, entre otros, les fue retirado el título. Sin embargo, Fernando Rosales, nombrado maestro albañil el 31.Mar.1782, lo conservó (cf. SuÁrez Garmendia, Arquitectura y urbanismo, 70-72).

9 Acomodándose al nuevo ambiente neoclásico, Antonio de Figueroa dejará como obra póstuma la nueva portada principal de la parroquia de Santa María la Blanca de La Campana, proyectada en diciembre de 1792, cuya terminación certificaría Fernando Rosales el 17 de diciembre de 1794.

10 La Academia daba por hecho "la existencia de dos categorías distintas entre los profesionales de la arquitectura: los arquitectos y los maestros de obras. Aquellos constituían, así pues, un cuerpo superior, porque debían poseer no solo la teoría, sino también la práctica para lograr el conocimiento de la posibilidad y seguridad de lo que dispusieran": José Enrique García Melero, "El debate académico sobre los exámenes para las distintas profesiones de la Arquitectura (1781-1783)", Espacio, Tiempo y Forma. Serie VII. Ha del Arte 6 (1993) 340 (325-378): https://doi. org/10.5944/etfvii.6.1993.2212.

11 Reconstrucción de las iglesias ecijanas de Santa Bárbara (Archivo Real Academia de Bellas Artes de San Fernando, en adelante ARABASF, Comisión de Arquitectura: 3-139, junta ${ }^{\circ} 64$ de 30 de marzo de 1790) y San Juan (junta n 67 de 12 de junio de 1790), nueva iglesia parroquial de Castaño del Robledo (junta $\mathrm{n}^{\circ} 69$ de 22 de septiembre de 1790), ampliación de la de Trebujena (junta nº 78 
Fernando Rosales también fueron inmisericordes con este, a pesar de su pertenencia a la Academia de las Tres Nobles Artes de Sevilla.

El primero de sus proyectos supervisados por la Comisión fue el de la nueva parroquial de La Nava, a cuyos planos no acompañaba memoria alguna. Además de esta carencia, en la junta de 22 de diciembre de 1794 los académicos denunciaban "repetidos resaltos sin necesidad, mal gusto de ornatos en su fachada, y por ultimo poca solidez en la espadaña que la corona" ${ }^{12}$ Finalmente sería encomendado al arquitecto académico D. Pedro García. ${ }^{13}$

El siguiente proyecto del maestro mayor enviado a la Comisión de Arquitectura fue el de la nueva iglesia de Villanueva de los Castillejos, acompañando a la memoria explicativa tres planos de planta, alzado y sección. El 11 de mayo de 1796 se rechazó el proyecto del "Alarife Fernando Rosales", por falta de solidez, mala ubicación de la torre y exceso adornativo, proponiendo se encomendase a un arquitecto titulado. ${ }^{14}$

Por último, ya avanzada la nueva centuria, en la junta de 9 de junio de 1816 vería rechazados sus proyectos para la reconstrucción de las iglesias hispalenses de Santa Cruz y la Magdalena (derribadas durante la ocupación francesa), al estar"firmados por Fernando Rosales sugeto desconocido que no consta sea aprobado por ninguna de las Reales Academias" y carecer "de informes facultativos y calculos de su costo y sus diseños de las debidas proporciones y decoracion correspondiente a buen orden de Arquitectura" ${ }^{15}$

de 21 de junio de 1791) y reconstrucción de la de Galaroza (junta n ${ }^{\circ} 90$ de 27 de junio de 1792).

12 Ibídem, Junta $\mathrm{n}^{\mathrm{o}} 117$

13 Ibídem, Junta n 119 de 13 de abril de 1795.

$14 \quad$ Ibídem, Junta $\mathrm{n}^{\circ} 125$.

15 ARABASF: Acta de Sesiones de la RABASF, año 1816, Junta Ordinaria de 9 de junio de 1816. Respecto de la intransigencia de la Real Academia con los proyectos de los maestros sevillanos, cf. OlLERO LOBATO, Cultura artística y arquitectura, $181-192$ y $383-403$. 


\section{ORÍGENES FAMILIARES, APRENDIZAJE Y COMIENZOS PROFESIONALES DE FERNANDO ROSALES}

La práctica totalidad de los maestros que precedieron a Fernando Rosales en la maestría mayor de la Iglesia de Sevilla, nacieron o se criaron en el seno de familias de alarifes. Fernando de Rosales y Ramos $\left(1754^{16}-1830\right)$ no iba a constituir la excepción, ya que fue el primogénito del maestro albañil Alejandro Rosales — cristianado en 1725 en la sevillana collación de San Martín ${ }^{17}$ - , con el cual aprendería la práctica del oficio. A finales de enero de 1752, Alejandro contrajo matrimonio en la iglesia de San Julián con Inés Josefa Ramos, doncella de veintiún años, trasladándose ambos a la collación de Santa Marina, en la que nacerían todos sus hijos. ${ }^{18}$ La familia Rosales residió en dicha collación hasta después de 1773, pasando posteriormente a la de Omnium Sanctorum.

El año 1775 ingresó Fernando Rosales como alumno en la Escuela de las Tres Nobles Artes de Sevilla, a cuyas clases asistió ininterrumpidamente hasta 1785, recibiendo el 14 de julio de 1778, de manos de D. Francisco de Bruna, el primer premio de arquitectura con el dibujo

16 La partida bautismal se ha perdido, pero sus declaraciones de edad apuntan a su nacimiento en 1754. En su examen de maestro albañil (31.Mar.1782) dice ser de edad de 27 años, que corresponde al nacimiento en 1754 o 1755. En el expediente matrimonial de su hermana Joaquina, de fecha 15.Dic.1803, afirma tener 49 años, de donde se deduce el nacimiento en 1754 . Por otra parte, en la partida de su entierro (16.Feb.1830), menos fiable, se dice que falleció a los 74 años, lo que supondría haber nacido en 1756. Lo más probable, pues, es que Fernando Rosales naciera entre abril y diciembre de 1754.

17 Archivo Parroquial de S. Andrés-Parroquia de S. Martín (en adelante APSMMSPSMS), Libro 8 de bautismos, F. 251v. Partida de bautismo de Alejandro Rosales. Inédito. Sevilla, 2.Dic.1725: "En Sabado dos de Diziembre de mil Setezientos y Veinte y cinco años yo $\mathrm{D}^{\mathrm{n}}$. Francisco Jiron, Cura de esta $\mathrm{Yg}^{\mathrm{a}}$. Parroquial de $\mathrm{S}^{\mathrm{r}}$. $\mathrm{S}^{\mathrm{n}}$. Martin de Sevilla, Baptizé a Alexandro Gregorio Francisco Antonio, hijo de Francisco Rosales y de Ana Mazias, Su Legitima muger: fue su padrino Alexandro Jurado, vecino al Sagrario de la Sta. Yga . advertile el parentesco espiritual y la obligacion de enseñarle la Doctrina Christiana a falta de sus padres, y lo firmé fecho ut Supra $=D^{\mathrm{n}}$. Francisco Jiron Cura".

18 En Santa Marina se registran los bautizos de ocho hijos de Alejandro e Inés, faltando el de Fernando Rosales, que nacería entre 1752 y 1756, cuyo libro se perdió. Esta es la lista de hijos: Juliana, Juan José, Antonia, Josefa, Alejandro e Inés, Gertrudis y Joaquina. Nótese que entre los hermanos de Fernando Rosales está Juan José, nacido el 25.Nov.1761, quien como se ha dicho también llegaría a ser maestro mayor del arzobispado de Sevilla. 
de un capitel corintio. ${ }^{19}$ En 1790 volvería a dicha Escuela, donde permanecería tres años más. ${ }^{20}$

Dio sus primeros pasos en relación con la albañilería bajo las órdenes de José Álvarez, como aparejador en las obras de la nueva parroquial sevillana de San Bernardo (1780-1785), en las que asimismo trabajaron su padre Alejandro y su hermano Juan José. ${ }^{21} \mathrm{~A}$ partir de 1781 se le documenta en las reparaciones del templo utrerano de Santiago. ${ }^{22}$ Fernando Rosales alcanzaría la maestría precisamente en este período, declarando en su examen de maestro albañil, celebrado el 31 de marzo de 1782, que"de quince (años) a esta parte está usando dicho Arte por haverlo aprendido con el referido su Padre que es Maestro de el en esta Ciudad". ${ }^{23}$ Oficiaron como Alcaldes Alarifes Bernabé Romero y Manuel Tamayo, mientras que José González y el ya veterano maestro mayor de la diócesis, Antonio de Figueroa, lo hicieron como examinadores. En la carta de examen se describe a Fernando Rosales como "pequeño de cuerpo color trigueño claro pelo castaño ojos pardos serrado de barba con una Zicatriz en la frente y de edad de veinte y siete años". Estaba claro que en el ambiente constructivo sevillano aún no habían calado las Reales Órdenes, prevaleciendo el poder de la institución gremial, en la que había que integrarse para poder practicar la profesión. ${ }^{24}$

19 Cf.Antonio Muro Orejón, Apuntes para la historia de la Academia de Bellas Artes de Sevilla, Sevilla, Real Academia de Bellas Artes de Santa Isabel de Hungría, 1961, 20-21. El examen previo consistió en el proyecto de"una casa para academia, con las divisiones y salas correspondientes para las clases y oficinas, con dos plantas, baja y alta, diseño de la fachada y coste del edificio".

20 También asistieron a la escuela de las Tres Nobles Artes Juan José y Francisco de Paula (Cf. Ollero Lobato, Cultura artística y arquitectura, 383), hermano y sobrino, respectivamente, de Fernando.

21 Cf. Teodoro Falcón MÁrquez, "El edificio barroco de la iglesia de San Bernardo de Sevilla", Laboratorio de Arte 32 (2020) 95-118: http://dx.doi.org/10.12795/ LA.2020.i32.06.

22 Cf. Fernando Quiles García, "Datos para una definición de la arquitectura neoclásica sevillana", Academia, Boletín de la Real Academia de Bellas Artes de San Fernando 84 (1997), 307-334.

23 Archivo Histórico Municipal de Sevilla (en adelante AHMS), Sección XVI, Carp. 1663, Caja 174, Doc. 194, F. 235r-v.

24 Unas décadas después esta situación habría cambiado radicalmente, retirándose en 1816 los títulos otorgados por el gremio desde 1787. Para entonces, Fernando Rosales, que conservó el suyo, era un destacado miembro de la institución académica sevillana. 
Fernando Rosales comenzaría a trabajar a las órdenes del arzobispado de Sevilla siendo todavía alumno de la Escuela de las Tres Nobles Artes, ya que fue nombrado maestro mayor el 12 de junio de $1784 .{ }^{25}$ Su primera intervención de importancia en el cargo, mal interpretada por la bibliografía existente, se produjo en la localidad onubense de Villanueva de las Cruces, donde dieciséis años atrás, el 30 de agosto de 1768, Antonio de Figueroa "precenttó Un plano, diciendo ser el que se debe executtar en la nueba costtrucion de dicha Ygla ", valorándola y dando las condiciones para la ejecución del templo. ${ }^{26}$ Las obras de la pequeña iglesia de una nave, presupuestadas en 57.000 reales, comenzaron rápidamente, declarando Ambrosio de Figueroa el 26 de marzo de 1770 el cumplido de estas.

Sin embargo, el 18 de junio de 1784 el párroco y el Ayuntamiento de Villanueva de las Cruces informan al arzobispado "...que la Yga . Parrochial de dicho Pueblo se halla ruinosa, y en imminente peligro los feligreses que la frequentan, por que a causa de las muchas aguas se ha quarteado y descuvierto varias averturas, que si de pronto no se remedian, amenazan su ruina proxima...", ${ }^{27}$ proponiendo el procurador mayor del Cabildo catedralicio el día 23 "que el Maestro mayor Fernando Rosales pase a la Citada Villa, y reconosca dicha Yga y declare las obras que necesita y su Costo, y del modo que mejor se pueden executar...". ${ }^{28}$ El 6 de julio de ese año, Rosales, "Maestro mayor de Obras de ellas Fabricas de las Yglesias de esta dicha Ciudad y su Arzobispado", declaró haber reconocido el mal estado de la iglesia, cuyos"Muros son de Mamposteria de mui mala Calidad las Mesclas

25 Fue nombrado "de aucencias y enfermedades" de los otros maestros mayores, como más adelante aclararía el propio Rosales:"En 12 de Junio de 1784 se despachó Titulo de Maestro mayor de Alarife de las Fabricas de lasYglesias Parroquiales de esta Ciudad y Arzobispado a Fernando Rosales" (Archivo General del Arzobispado de Sevilla, en adelante AGAS-Medios de información-Leg.16427, F. 1r). Según SANCho Corbacho, Arquitectura barroca sevillana, 263, el nombramiento en propiedad lo obtuvo el 3.Feb.1795. Sin embargo, el 30.Mar.1795 se seguía declarando"Maestro maior de obras de Albañileria de las Fabricas de las Yglecias de esta dicha Ciudad y su Arzobispado (por auciencias y enfermedades de los dos nombrados por elYltmo Señor Dean y Cabildo de esta Sta y Patriarcal Yglecia" (AGAS, Justicia, Pleitos ordinarios, Leg. 10150, F. 87v-88r.).

26 Archivo Diocesano de Huelva (en adelante ADH), Villanueva de las Cruces, Justicia, Clase 2a , Leg. 549, F. 7r-13r.

27 Ibídem, F. 4r-5r.

28 Ibídem, F. 6r. 
de su Construccion pues dan a entender están construidas con Tierra; y en caso que tuvieran alguna Cal, fué mui poca, y es la razon que han padecido los citados muros y en particular el Cañon que cubre la Nave que ya va dicha es de Rosca de Ladrillo, pues se haya tan quebrantado que es preciso derribarlo".$^{29}$ Prescribe sustituir la bóveda de cañón de la nave por una armadura de madera, así como rehacer las cubiertas de sacristía, cuarto taller y capilla bautismal. Sin embargo, tras una nueva visita a la iglesia, el maestro declara el 26 de noviembre"que en atencion que los dichos simientos no son de lo mas suficiente, ni las referidas paredes de la construccion ni calidad que corresponde, fuera mas combeniente construyrlas de nueva fabrica", proponiendo desplazar la nueva iglesia veinte varas para poder profundizar más los cimientos, de tal manera que "teniendolo Usias a bien que se construya de nueva fabrica la dicha $Y^{a}{ }^{a}$., esta pronto a formar Plano con la misma Longitud y Latitud, y demas oficinas que en el dia tiene, pues las concidera suficiente para el besindario", valorando la reconstrucción en 70.000 reales de vellón. ${ }^{30}$ Las obras fueron autorizadas, dando comienzo el 3 de octubre de 1784. El templo que Antonio de Figueroa había construido entre 1768 y 1770 fue derribado, encontrándose abierta la nueva cimentación el 11 de marzo de $1785 .{ }^{31}$ Rosales expuso en su informe de visita de 7 de junio la situación de las obras, en las que se llevaban invertidos 17.000 reales. ${ }^{32}$ La iglesia erigida bajo las trazas y la supervisión de Rosales, de una sola nave y capillas hornacinas, fue terminada el 31 de mayo de 1788, alcanzando un coste de 86.370 reales. ${ }^{33}$ Su interior es un trasunto a escala reducida del de la parroquial de Santa Bárbara de Casa (1770-76), lo cual se explica por deberse esta a Ambrosio de Figueroa, padre y maestro de Antonio, y haber construido Rosales la de Villanueva de las Cruces respetando formalmente el edificio precedente. Queda pues añadido este templo al catálogo de obras de Fernando Rosales. ${ }^{34}$

\footnotetext{
Ibídem, F. 11r-12r.

Ibídem, F. 25r-26v.

Archivo Catedral de Sevilla (en adelante ACS), Fondo Capitular (en adelante FC), Contaduría, Leg. 11667, Exp. 13.

$32 \mathrm{ADH}$, Villanueva de las Cruces, Justicia, Clase 2a, Leg. 549, F. 35r-36r.

33 Ibídem, F. 47r.

34 Noticia que aquí se da por vez primera, refutando lo expuesto en SANCHO Corbacho, Arquitectura barroca sevillana, 224, y en Ollero Lobato, Cultura artística
} 


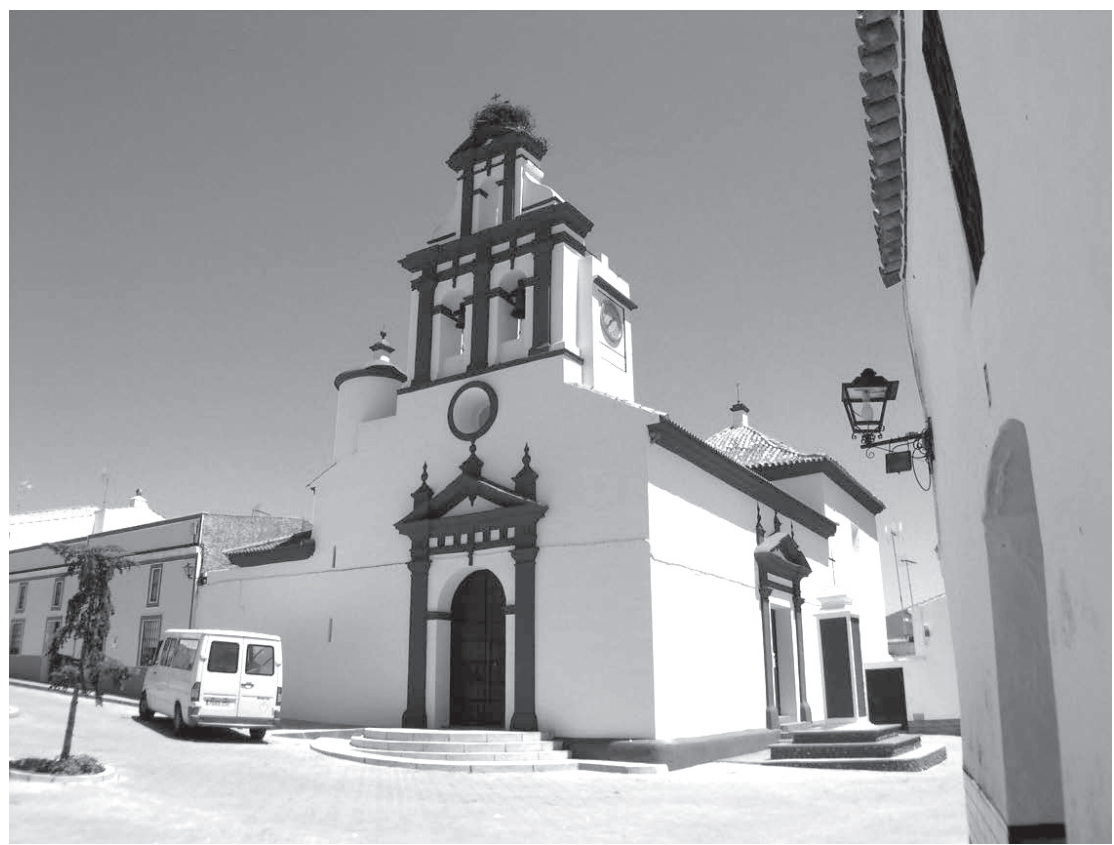

Figura 1. Iglesia parroquial de Villanueva de las Cruces, reedificada junto al solar de la anterior por Fernando Rosales entre 1785 y 1788. Fotografía del autor.

El maestro acometería otras dos intervenciones de importancia en 1784, ambas sobre edificios preexistentes. La primera fue en la parroquial de San Juan Bautista de San Juan del Puerto. En su informe de 11 de julio de 1784 prescribía dotar de nuevo aspecto a las portadas y cómo finalizar la nueva capilla bautismal, proyectada en 1782 por el maestro mayor José Álvarez en la ampliación de la iglesia mediante el añadido de un cuerpo a los pies. ${ }^{35}$

y arquitectura, 395, donde se atribuye a Figueroa y no a Rosales la reconstrucción del reciente y arruinado templo.

35 Cf. Manuel J. Carrasco Terriza, "Patrimonio histórico-artístico de la iglesia parroquial de San Juan Bautista (ss. XVI-Xx)", en David GonzÁlez Cruz (ed.), Cinco siglos de historia de la villa de San Juan del Puerto (1468-1992): de la tradición marítima al proceso de industrialización, San Juan del Puerto, Ayuntamiento de San Juan del Puerto, 1992, 353-386; y Manuel J. CARRASCo TERRIZA - Juan M. GonZÁLEZ Gómez, Catálogo monumental de la provincia de Huelva, Vol. II, Huelva, Univ. de Huelva, 2010, 172-173. 


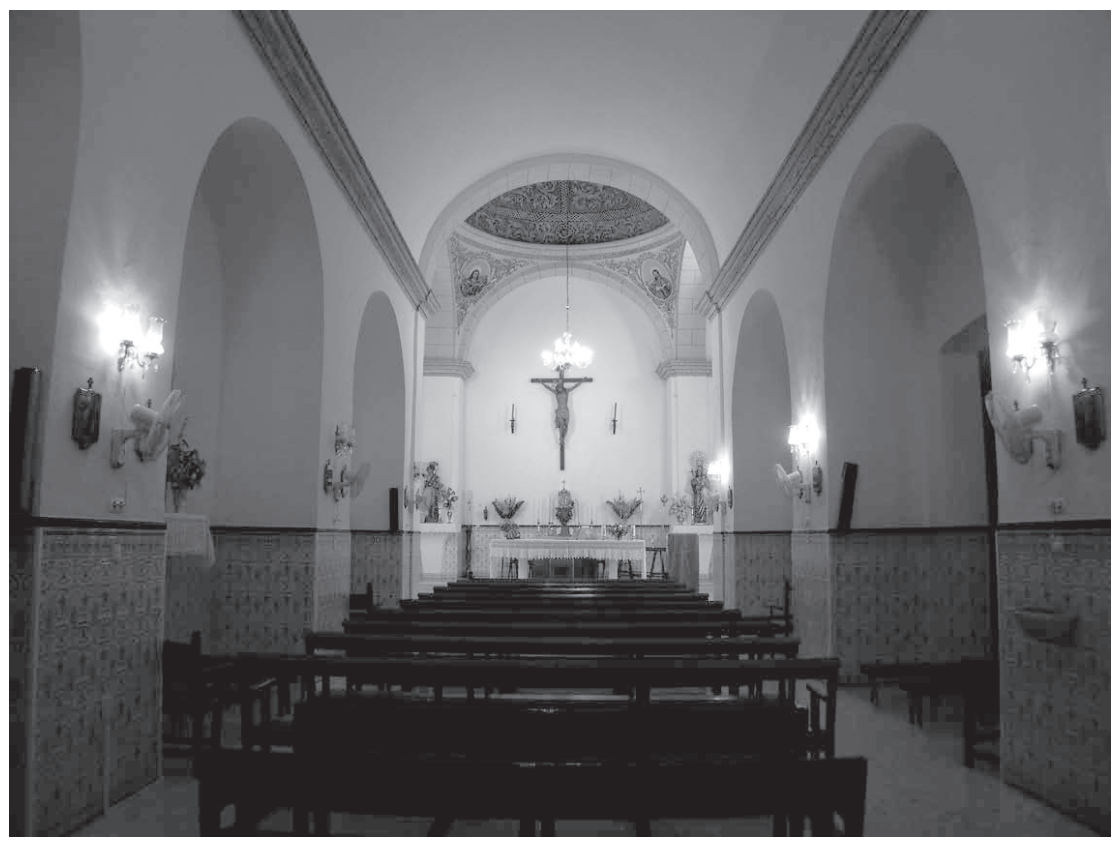

Figura 2. Iglesia parroquial deVillanueva de las Cruces. Interior. Fotografía del autor.

En cuanto a las portadas del templo, finalizadas a primeros de 1785, Rosales las proyecta en orden dórico, al igual que en el caso de Villanueva de las Cruces. Sin embargo, al ser un edificio de mayor porte que el modesto del Andévalo, las dota de más elementos decorativos y jerarquiza su formalización en función de la representatividad y protagonismo del ambiente urbano al que recae cada una de ellas. Así, a la portada de la epístola, que afronta a una extensa plaza, se le otorga mayor relevancia y relieve mediante semicolumnas que sostienen un entablamento con sus correspondientes triglifos y metopas; sobre el frontón curvo y partido descuella un frontoncillo triangular que marca el eje, rematando el conjunto tres elementos cerámicos. Además, una moldura recta enmarca la puerta. Por su parte, al recaer a una estrecha calle, la portada del evangelio es mucho más sencilla en relieve y ornamentación: dos pilastras dóricas sostienen un entablamento con triglifos en los ejes de pilastras y de portada y 
un frontón triangular con un escueto pinjante en el tímpano, quedando rematada por los característicos elementos cerámicos. ${ }^{36}$

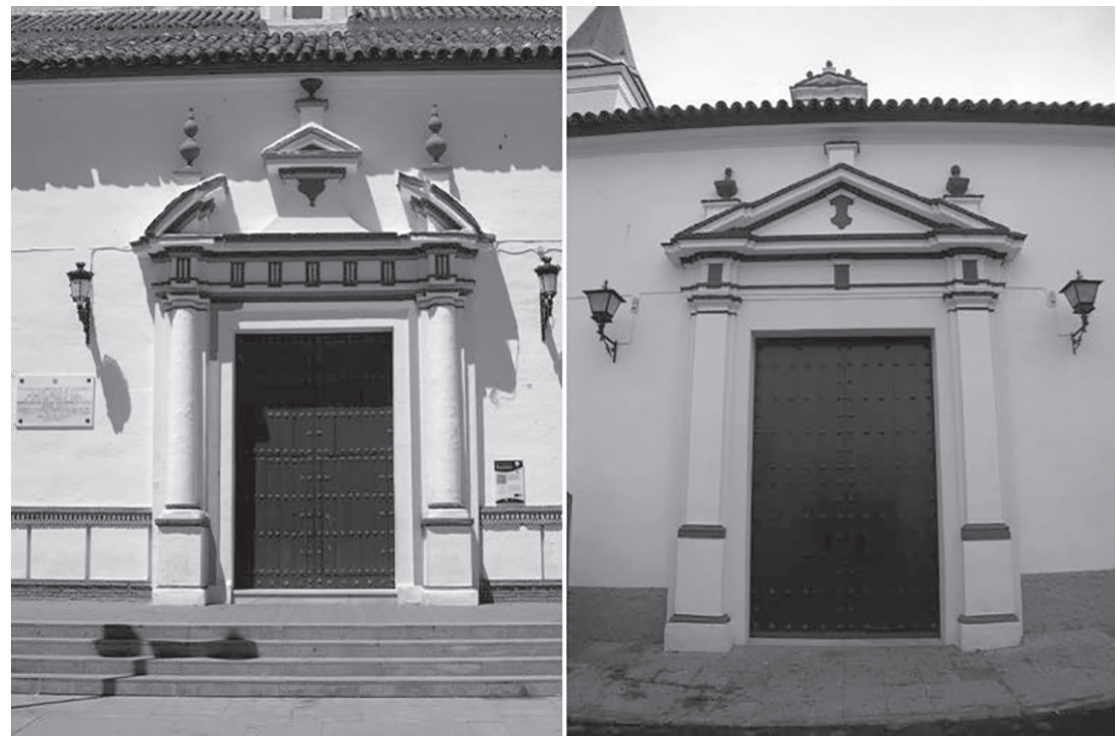

Figura 3. Iglesia parroquial de S. Juan Bautista en San Juan del Puerto. Portadas de la epístola (izq.) y del evangelio (dcha.), realizadas por Fernando Rosales entre 1784 y 1785. Fotografías del autor.

La otra intervención relevante de Rosales en 1784 fue la ampliación de la iglesia de Nuestra Señora de los Remedios de Cortelazor la Real, del tipo serrano con arcos transversales diafragmáticos, donde proyectó una nueva fachada con portada, óculo y espadaña. El 25 de mayo de 1787 propuso su sustitución por una torre, estando prácticamente finalizadas las obras en mayo de $1792 .{ }^{37}$

36 Rosales adoptará estos modelos de portadas, más o menos elaborados, para sus edificios religiosos. Antonio de Figueroa advertía para evitar el gasto en adornos superfluos: "...llevando de la mano el ornato de la Portada que mira a la Plaza, que la otra no lo Necesita (aunque en el dia lo tiene) Pero mediante a que la dicha cae al exio está de mas gastar los dineros donde no hay lucimiento ni Necesidad...", AGAS, Justicia, Pleitos ordinarios, Leg. 11986 (Pruna), F. 14r-19v. 18.May.1779.

37 Cf. Alfonso Pleguezuelo Hernández - Alberto Oliver Carlos, "Historia constructiva de la iglesia parroquial de Nuestra Señora de los Remedios de Cortelazor (Huelva)", en Neftalí Santos Bravo (ed.), V Jornadas de Patrimonio de la Sierra 
El maestro no descuidaba sus obligaciones corporativas: el 28 de marzo de 1785 Fernando Rosales obtuvo el cargo de veedor alarife del Gremio, nombramiento que compartiría con José Echamorro. Como examinadores resultarían elegidos Luis Martínez y Nicolás González.38

\section{INTERVENCIONES EN SAN EUTROPIO DE PARADAS, EL SALVADOR DE CARMONA Y LAS PARROQUIALES DE VALENCINA Y LOS PALACIOS. ROSALES SOLICITA LA MAESTRÍA MAYOR DE LA CIUDAD}

En 1785, el maestro mayor reformaría y ampliaría el proyecto de extensión de la iglesia de San Eutropio de Paradas, realizado por José Álvarez dos años atrás, obteniendo previamente el visto bueno del propio José Álvarez y de Antonio de Figueroa. ${ }^{39}$

Figueroa apreciaba y reconocía el buen hacer de Fernando Rosales, declarando en su informe de visita del 28 de noviembre de 1788 que la obra llamaba la atención "por el buen arte y simetria con que le parecio estar determinado y egecutado, como en efecto mientras mas se aprosimaba, de mejor aspecto dise que le parecia", añadiendo "siertamente que no se puede mejorar la bista esterior de este edificio. ${ }^{40}$ El 19 de agosto de 1790, el mismo Antonio de Figueroa daba el cumplido, añadiendo que "ha finalizado con el mejor arte y aceo la referida obra". ${ }^{41}$

A finales de 1779 se produjo el derrumbe accidental de la antigua parroquial de Ntro. Señor San Salvador de Carmona, durante el transcurso de unas obras de reparación prescritas y ejecutadas por Pedro de Silva, quien en su informe de 2.Nov.1779 describía cómo

de Huelva (1990, Almonaster la Real), Huelva, Diputación de Huelva, 1994, 135148. Cf. también Archivo Histórico Provincial de Sevilla (en adelante AHPS), Fondo de Protocolos Notariales (e.a. FPN), Of. 19, Libro $1^{\circ}$ de 1789, Sign. 13183, Registro 19, F. 352r. Imposición de tributo para la obra de la iglesia parroquial de Cortelazor.

38 AHMS, Sección 5a, Leg. H-1157.

39 AGAS, Justicia, Pleitos ordinarios, Leg. 10312, F. 87v-88r.

40 Ibídem, F. 133r-188v.

41 bídem, F. 658r-659r. Sobre el proceso constructivo del templo, Cf. Álvaro PASTOR Torres, "Planos inéditos de la iglesia de San Eutropio de Paradas", Atrio, Revista de Historia del Arte 3 (1991), 151-160. 
se había producido el hundimiento. ${ }^{42}$ El veterano maestro mayor es propuesto para que forme" plan y ponga Condiciones Con toda claridad valuando el costo que Podra tener la dicha nueva Obra", a fin de reedificar lo arruinado.

Sin embargo, el 24 de abril de 1780, las diligencias quedan suspendidas "hasta tanto se resuelve por el Real Consejo la instansia de que se conceda la $\mathrm{Yg}^{\mathrm{a}}$ de los Regulares extinguidos para que sirva de Parroquia (...) todo se puede remediar si se logra la Yglesia de dichos Regulares, que está dentro de la collazion y de las mas decentes y de buena Arquitectura y que a poquissimo costo se podrá poner corriente" ${ }^{43}$ Es decir, dado que ni la empobrecida fábrica parroquial ni los partícipes en los diezmos podrían asumir el elevado coste de la reedificación, se solicita la cesión de la antigua iglesia de la extinguida Compañía de Jesús para reubicar allí la parroquia. ${ }^{44} \mathrm{El}$ 1 de julio de 1785 se informa que ya se había"dignado la piedad del Rey (que Dios guarde) concederles la que fue de los Regulares de la compañía extinguida para su establecimiento", y dos meses después se autoriza que el maestro mayor que estuviese en turno visitase la iglesia, "Y declare si las Bovedas y Enterramientos que dicha Yglesia tenga son o no suficientes para los entierros que puedan ocurrir, segun la extencion de su Feligresia"y las reparaciones que precisaba el templo. Tocó en turno a Fernando Rosales, que en su informe de 24 de noviembre describe el estado del templo, así como los destrozos causados en la linterna por un rayo, valorando la reparación de lo dañado en 2.400 reales. Proyecta las tacas, archivo, comunes, nuevo cuarto taller y nuevas escaleras para subir a las tribunas. No encuentra con suficiente capacidad las bóvedas de enterramiento existentes, estando "pronto a formar Plano y condiciones juntamente con sus aprecios a que podrá assender, como ansimismo de todas las demas

42 AGAS, Justicia, Pleitos ordinarios, Leg. 10724, F. 77r-81r.

43 La antigua iglesia del Colegio de San Teodomiro, levantada entre 1700 y 1720 por el alarife sevillano Pedro Romero (1633-1711) y sus hijos, estaba sin uso desde la expulsión de los jesuitas en 1767, habiendo sido desmantelada y repartidos sus principales retablos, imágenes y enseres entre las parroquias y conventos de Carmona.

44 La parroquia del Salvador ya se había trasladado al templo de los jesuitas el 20 de abril de 1783. Cf. Esteban Mira CABAllos, "Historia de la antigua iglesia y parroquia de El Salvador de Carmona", en Investigaciones Indianas: https://estebanmira.weebly.com [Consultado: 10 de abril 2021]. 
Obras que lleva declaradas", valorando los materiales hallados en la antigua iglesia parroquial entre 16.000 y 18.000 reales de vellón. ${ }^{45}$

Once meses más tarde, el provisor del arzobispado mandó "formalize el Maestro mayor Fernando Rosales el Plano y condiciones de un Campo Santo capaz a la colocacion de los cadaveres de los Feligreses de la citada Yglesia", fuera de los muros de la ciudad, y su coste, así como"manifieste la cantidad a que ascendera la execucion de las Obras que proyecta en su visita".

De esta manera, el 21 de noviembre de 1786 el maestro Rosales presenta el magnífico plano (figura 4), ${ }^{46}$ así como las condiciones para ubicar el cementerio, proponiendo emplazarlo bien junto a la ermita de San Mateo, bien en el Alcázar viejo, más cómodo que el anterior" por no tener que vaxar cuesta alguna". Por lo que a las obras de la iglesia se refiere,

tuvo por combeniente el que declara formar Plano de toda su capasidad y repartimiento, demostrando con el color oscuro el total del Templo con sus ofisinas Segun y conforme a las proporciones que actualmente tiene; Con el paxizo el Area de la $\mathrm{Yg}^{\mathrm{a}}$ que antiguamente tenian los padres antes de construir la que el dia es Parroquia, y con el color Encarnado se dexa ver las Puertas que se debe tapar para la separacion de los Claustros a las Oficinas de esta Yga; Assimismo el Sitio de las tacas y Archivo, quarto taller, Escalera para las tribunas y el sitio donde quedan los comunes, expresando tambien en el dicho Plan cada una de sus partes por sus numeros y Notas.

Las obras fueron valoradas en 18.500 reales de vellón y obtuvieron licencia el 12 de enero de 1787. Tras el seguimiento por el propio Rosales de los trabajos de restauración del templo, que se dilatarían cerca de diez años, dio el maestro su cumplido el 11 de junio de 1796.

\footnotetext{
45 AGAS, Justicia, Pleitos ordinarios, Leg. 10724, F. 284r-289r.
}

46 Ibídem, F. 315. 


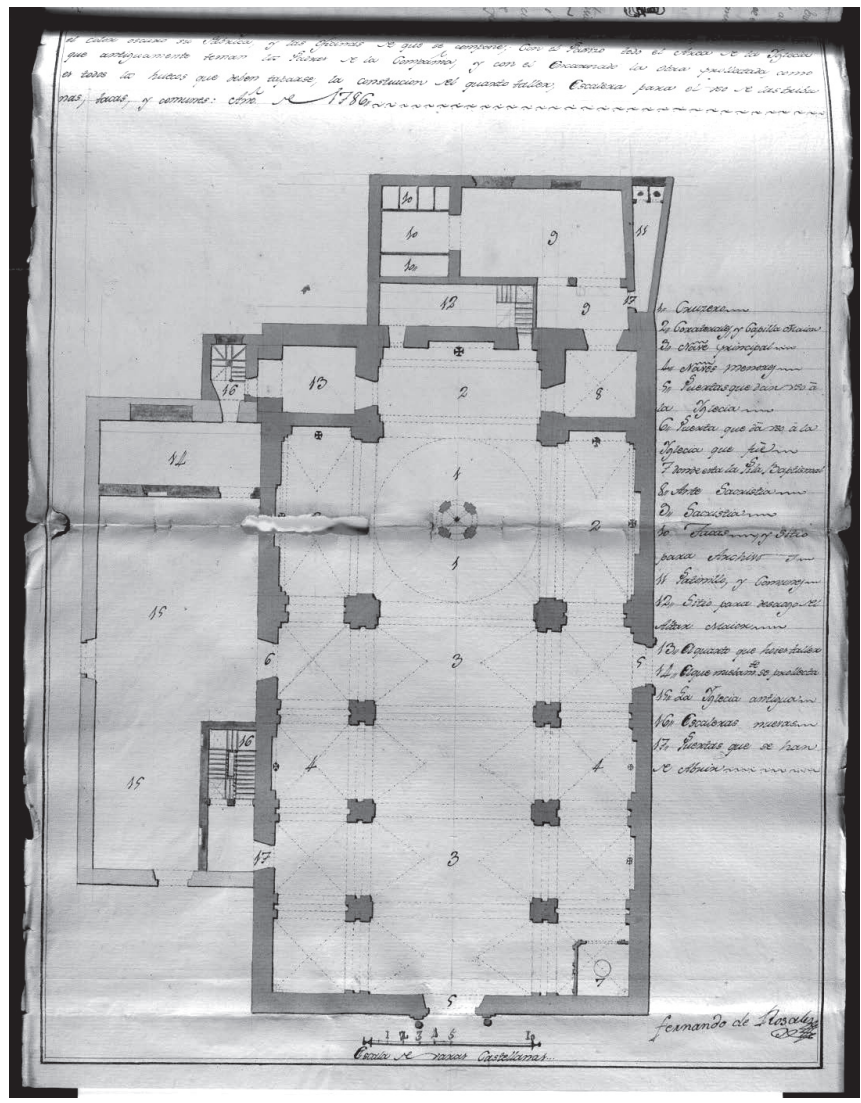

Figura 4. Planta de la iglesia carmonense de San Salvador, levantada por Fernando Rosales en noviembre de 1786. AGAS, Fondo Arzobispal, Sec. III, sign. 10724. (C Cabildo Catedral de Sevilla.

La relevancia de esta intervención desconocida de Fernando Rosales en Carmona estriba en que muestra a las claras el compromiso en el ejercicio de su cargo del aún joven maestro mayor de apenas treinta y un años, primero realizando con presteza y minuciosidad los informes de obras previos y sus valoraciones $\mathrm{y}$, segundo, ofreciéndose de inmediato a plasmarlas en el correspondiente plano, en este caso, primoroso y detallado. Además, se da a conocer así el estado que presentaba por aquel entonces el imponente templo del antiguo Colegio de San Teodomiro. Finalmente, no es de menor consideración la valentía con que asume Rosales la 
responsabilidad de acometer la rehabilitación y restauración de un edificio de semejante porte.

Aparte de su nombramiento como maestro mayor del arzobispado, Fernando Rosales también optaría a la Maestría Mayor de la Ciudad. El 3 de abril de 1786 presentó su instancia para ocupar la plaza dejada libre por desistimiento de Félix Caraza y en sesión celebrada el día 6 le fue adjudicado el puesto por votación a José Echamorro, que obtuvo once votos, en tanto Rosales consiguió solamente dos. ${ }^{47}$

A mediados de 1787, la villa de Valencina o Valencina del Alcor ${ }^{48}$ denunciaba el mal estado de las cubiertas de su vetusta iglesia parroquial, que había sido reformada por Diego A. Díaz en $1731{ }^{49}$ dando cuenta de ello el provisor el 18 de septiembre. ${ }^{50}$

En su informe de 11 de octubre de 1787, Fernando Rosales describe un templo de tres naves, con capilla del Sagrario, otra del Santísimo Cristo de la Humildad, sacristía, un cuarto taller posterior a la gualdera de la epístola y torre junto a la puerta del evangelio, "todo de obra antigua y de mas de segunda vida". El maestro prescribe la reconstrucción de los tejados de las naves y de la escalera de la torre. Las obras comenzaron el 7 de julio de 1788.

Sin embargo, iniciados los trabajos, Rosales expone la necesidad de aumentar las obras inicialmente previstas, pues es preciso demoler y reconstruir la gualdera de la epístola, las paredes de la sacristía y las de la capilla contigua a esta. A tal efecto, el maestro delinea el presente inédito plano, en el que se muestra una iglesia de tres naves de igual longitud con cabeceras planas, cuatro pilares de planta cuadrada por banda, intercolumnios de vanos desiguales y capillas y servidumbres (sacristía, cuarto taller, torre) adosadas al cuerpo principal de manera desordenada; y, como llamativa particularidad, la exagerada convergencia hacia el presbiterio de las líneas de arcos. ${ }^{51}$

47 AHMS, Sec. 10 ${ }^{\text {a }}$ Leg. H-1876, Libro de Actas Capitulares de 1786, Sesión de 6 de abril, F. 61r-63v.

48 En 1948 cambió la villa su topónimo al actual de Valencina de la Concepción.

49 Cf. Sancho Corbacho, Arquitectura barroca sevillana, 173.

50 AGAS, Justicia, Pleitos ordinarios, Leg. 10185.

51 Su interior debía recordar en cierta medida al de la parroquial de Castilblanco de los Arroyos. 


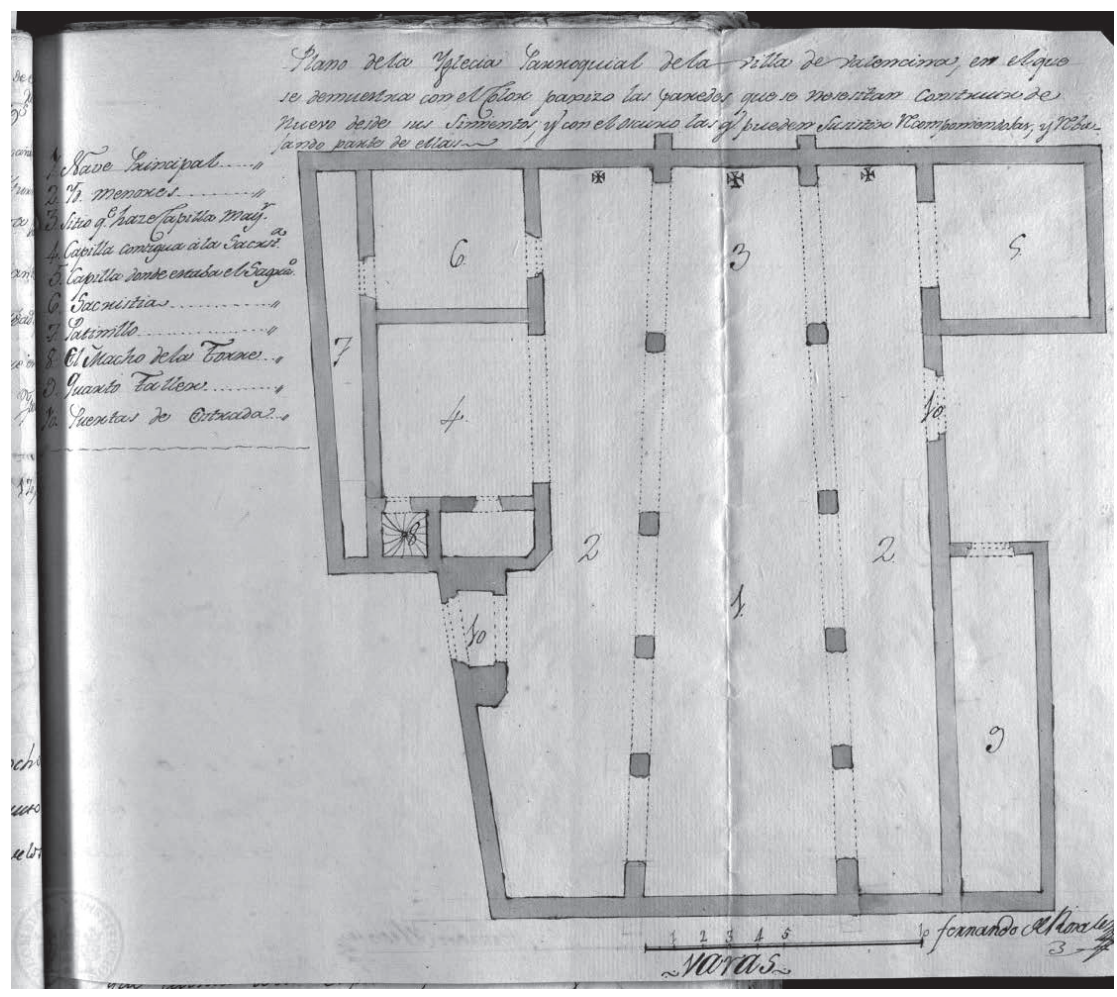

Figura 5. Planta de la antigua iglesia de Valencina, dibujada por Fernando Rosales en 1788. AGAS, Fondo Arzobispal, Sec. III, sign. 10185. (C) Cabildo Catedral de Sevilla.

Autorizadas las obras, fueron supervisadas por Fernando Rosales, que evacuó informes en agosto y septiembre de 1788 y en marzo de 1790, dando el cumplido el 27 de agosto de dicho año. Los trabajos habían finalizado el 20 de julio. ${ }^{52}$

En otro orden de cosas, el 16 de abril de 1789 ya constan Alejandro Rosales y su familia viviendo de alquiler en la calle Cerrajería, $n^{\circ} 321$ del Padrón $2^{\circ}$, collación del Salvador, en una casa propiedad del Cabildo

52 Estas obras fueron el germen de las ejecutadas a principios del siglo XIX, por las que se suprimieron las líneas de arcos, transformando el edificio en una iglesia de una nave y dándole la apariencia tardobarroca que muestra hoy. Dichas obras, finalizadas en 1819, serían muy probablemente proyectadas y dirigidas por los maestros mayores Santiago de la Llosa o Juan José Rosales. 
catedral,,$^{53}$ constituyéndose "Fernando Rosales del mismo Oficio vez ${ }^{\circ}$. de esta Ciudad su Hijo, como su Fiador y Pral. pagador" ${ }^{54}$ Allí permanecerán hasta 1795.

A pesar de su dedicación al servicio del arzobispado de Sevilla, Rosales no faltaba a los compromisos del gremio, concurriendo a las elecciones del 1 de abril de 1793 junto con su padre Alejandro y su hermano Juan José..$^{55}$

Volviendo a su labor constructiva, desde 1790 venían ejecutándose obras de reforma en la parroquial de Santa María de las Nieves de Los Palacios, iglesia columnaria de tres naves sin crucero. El 22 de abril de 1793 dio Rosales las condiciones para extenderla por los pies, tomando el espacio ocupado por el coro y la capilla bautismal y formando nuevo coro y tribuna para el órgano. La nueva torre se ubicó en una posición inusual, ya que se alza en el centro de la fachada, habiéndose prácticamente concluido la obra el 17 de septiembre de $1794 .{ }^{56}$

Respecto de la torre ejecutada por Rosales para la parroquial de Los Palacios, es preciso dejar constancia de la gran similitud que guarda su campanario con el cuerpo de campanas de la iglesia de San Martín de Tours de Bollullos de la Mitación, de tal manera que parecen ser uno copia del otro, como se puede apreciar en la figura. Bien es verdad que en el ejemplar palaciego el maestro no dispuso el cajeado y los paños de azulejos que hermosean el cuerpo de campanas de Bollullos, pero sí el denticulado tan característico de sus cornisamentos. Es posible, pues, que ambos campanarios sean coetáneos y debidos a la mano de Fernando Rosales, hipótesis que queda formulada.Y en cuanto al resto del templo de San Martín, bien podría deberse a Rosales su reforma y apariencia actual, pues en 1797 se estaban realizando importantes obras en él. ${ }^{57}$

53 AHPS, FPN, Of. 19, Libro $1^{\circ}$ DE 1789, Reg. 14, Sign. 13183, Fol. 505r-v. Inédito. En 1790 aparecen empadronados: “D. Alejandro Rosales, Da. Ynes Ramos, D. Fernando Rosales, $D^{\mathrm{a}}$. Antonia Rosales, $\mathrm{D}^{\mathrm{a}}$. Gertrudis Rosales y $\mathrm{D}^{\mathrm{a}}$. Juaquina Rosales".

54 AHPS, FPN, Of. 19, Libro $2^{\circ}$ DE 1792, Reg. 25, Sign. 13190, s.f. Inédito.

55 AHMS, Sección 5 ${ }^{\text {a }}$, Leg. H-1157.

56 AGAS, Justicia, Pleitos ordinarios, Leg. 2114, F. 168r-186v. Cf. Ollero Lobato, Cultura artística y arquitectura, 386-387.

57 "Estado actual de las Obras de las Yglesias cuia Administracion se halla al cargo de $\mathrm{D}^{\mathrm{n}}$ Josef Maria Rodriguez Presvo en este presente año de la fecha: (...) Bollullos de la Mitacion: Cargo 84.704 reales, Data 86.923 reales, Capitales 

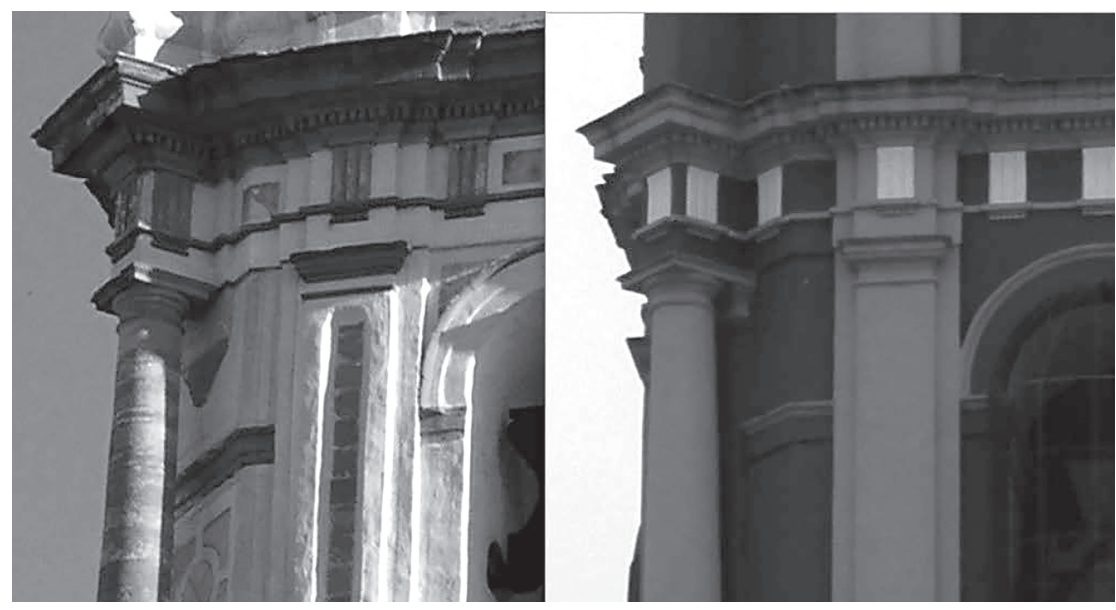

Figura 6. Detalle de los cuerpos de campanas de las parroquiales de Bollullos de la Mitación (izq.) y Los Palacios y Villafranca (dcha.). Las similitudes son evidentes. Fotografías del autor.

\section{SAN BARTOLOMÉ DE SEVILLA, SAN PEDRO DE PEÑAFLOR Y SANTA MARÍA DE UTRERA. DESENCUENTROS CON JOSÉ ECHAMORRO}

En 1792, Fernando Rosales era ya, además de maestro mayor de la fábrica de Omnium Sanctorum, ${ }^{58}$ un reconocido maestro entre los profesionales sevillanos de la construcción. En efecto, a primeros de septiembre de ese año, el maestro alarife Rafael de Ledesma remite un escrito al Arcediano de Sevilla y a la Diputación de Negocios del Cabildo catedralicio, en el que denuncia que, habiendo sido nombrado maestro para la continuación de las obras de la iglesia parroquial de San Bartolomé, está padeciendo las difamaciones del cura y del abad de los beneficiados parroquiales, ya que preferían "sea dirixida esta obra por uno de los famosos Maestros del Cavildo de V.S . quales son Alvares, Rosales..." ${ }^{59}$ El análisis del expediente de obra

219.132,30 reales (...) Sevilla 8 de Junio de 1797": ADH, Campofrío, Clase 2a ${ }^{\mathrm{a}} \mathrm{n}^{\circ}$ doc 3-5, Ramo $2^{\circ}$.

58 AGAS, Justicia, Pleitos ordinarios, Leg. 12764. Ejecución de obras en dos casas pertenecientes a la fábrica de Omnium Sanctorum. Proyecto de Antonio de Figueroa y dirección de Fernando Rosales.

59 AGAS, Justicia, Pleitos ordinarios, Leg. 11473, F. 140r-141r. 
de dicha iglesia parroquial, permite concluir que el actual aspecto de San Bartolomé responde en su interior al proyecto de Antonio de Figueroa, mientras que exteriormente (salvo posiblemente la portada de la epístola) todo refleja la intervención de Fernando Rosales, llevada a cabo entre 1793 y $1796 .{ }^{60}$

Al tiempo de su participación en las obras de San Bartolomé, a Fernando Rosales le iba a corresponder visitar las de la nueva iglesia de San Pedro Apóstol de Peñaflor, que a los catorce años de su inicio iban a recibir por fin la inspección de un maestro mayor de albañilería de la diócesis y que se hallaban paralizadas desde el 31 de marzo de 1788. El 7 de enero de 1794 evacua Rosales un informe en el que describe y valora pormenorizadamente el estado de la construcción, añadiendo que la obra ejecutada no tiene nada que ver con la proyectada ${ }^{61}$ La posterior intervención pericial de Fernando Rosales derivaría en un desencuentro de pareceres con José Echamorro (1750-1825), documentado y explicitado aquí por vez primera, a cuenta de cómo solucionar los daños que presentaba el edificio. Dicho enfrentamiento engendró en ambos maestros una latente enemistad que se pondría de manifiesto en posteriores obras diocesanas. ${ }^{62}$

En su citado informe, Rosales expone que los dos arcos botales suben hasta la altura de los arcos intercolumnios, como deben, "y como que estos dichos yntercolunios devieron subir solamente hasta las ocho varas y media poco mas, y lo restante fuese de maziso

60 Cf. Pilar Vilela Gallego, "San Bartolomé de Sevilla", Archivo Hispalense 222 (1990) 173-184; y cf. José Manuel Higuera MeléndeZ, "Sobre la construcción y restauración de la iglesia sevillana de San Bartolomé y su torre", Isidorianum 53 (2018) 155-178: https://doi.org/10.46543/ISID.1827.1010.

61 AGAS, Justicia, Pleitos ordinarios, Leg. 10534, F. 204r-209v. Sorprendentemente, las obras se habían ejecutado sin tener en cuenta el pliego de condiciones de Antonio de Figueroa y sin la supervisión de maestro mayor de albañilería alguno. De ahí la anómala configuración formal tanto externa como interior de la iglesia de Peñaflor que, paradójicamente, ha dado lugar a numerosas loas por parte de investigadores e historiadores del arte hacia Antonio de Figueroa, quien no tuvo nada que ver con la obra ejecutada. Lo cierto es que Figueroa fue despedido durante la apertura de los cimientos, siendo sustituido por el alarife ecijano Antonio Caballero, que reformó las trazas, dimensiones y volumetría del templo y ejecutó las obras. Cf. José Manuel Higuera Meléndez, "Nuevos datos sobre la autoría de la iglesia de San Pedro Apóstol de Peñaflor (Sevilla)", Laboratorio de Arte 31 (2019) 403-420: http://dx.doi.org/10.12795/LA.2019.i31.23.

62 Así ocurriría en Santa María de la Mesa de Utrera y, en menor medida, en la sevillana iglesia de San Ildefonso. 
de Pared, en la Nave del medio, y esquadra que forman los cruzeros o brazos, no pueden ni hacen la fuerza que devian hacer para contener el empujo de los Torales y gravedades", hallándose desplomados los pilares torales que principian la nave de la iglesia, tanto hacia las gualderas, el de la epístola con cuatro pulgadas y el del evangelio con tres, como también tres pulgadas hacia la nave. Rosales explica que "los citados Machos sin perder el todo de su plomo en los arranques de los Arcos que reciben, se han vareado" debido a "la desmaciada gravedad que estos reciben", hallándose por su cabeza "quarteados uno y otro que causa orror el mirarlos, considerando la gravedad que sobre estos se apoyan".

En cuanto a la sencilla media naranja propuesta en las condiciones, Rosales denunciaba que se ha construido un tambor"con unos gruezos de Paredes o Muros por partes de mas de a vara, adornado por lo interior y esterior, con sus Medias muestras de colunas (...) Las esteriores, de Ladrillo cortado, y las interiores de Yeso blanco", continuando la media naranja alimonada y linterna, por lo que consideraba el maestro"que de ningun modo podra subcistir esta obra, eYglecia con el citado cuerpo de Luzes, media Naranja y Linterna como oy está". Dictaminando finalmente "ser urgente el derrivo de dicha Linterna Media Naranja y Cuerpo de Luzes, hasta el Banquillo que está formado sobre el entablamento del Anillo, sin que se pueda continuar a nuevo cerramento, hasta que se reconosca nuevamente, y se vea si es preciso continuar dicho derribo, o aplicarle la cubierta mas ligera y sencilla". Valora en 115.000 reales de vellón lo que restaba por ejecutar.

Es fácil comprender la impresión que causaría en la Diputación de Negocios la declaración de Rosales, condenando al derribo una obra en la que se habían invertido seiscientos mil reales y lo que es peor, habiendo sido confidencialmente delegada por la propia institución fuera del ámbito del Cabildo y de los maestros mayores diocesanos.

En una primera comparecencia de los maestros Rosales y Manuel Talabán con los alarifes ecijanos Antonio Caballero, ejecutor de la obra, y Simón de Salazar, declaró Caballero que "no havia tenido, ni nunca tubo condiciones algunas ni Plano; y asi, que todo lo que alli se havia hecho, havia sido segun su idea o inteligencia, y que quando fue llamado para construir dicha obra, solo se le manifestó berbalmente por el Director, hasta donde se havia estender, con la Longitud y Latitud de toda la Yglecia, tomando de la Plaza, cierto sitio con la annuencia de las Justicias". Y mientras los maestros diocesanos 
insistían en el derribo del templo, Caballero y Salazar manifestaban que la iglesia quedaría asegurada macizando parcialmente los arcos de las capillas colaterales a la mayor. ${ }^{63}$

Dado que los maestros estaban "discordes en el modo y forma que se ha de remediar los defectos que se advierten mediante lo qual estamos en el caso de que se nombren tercero o terceros en discordia", siendo elegido a tal fin José Echamorro. Este evacuó informe el 5 de julio de 1794, dictaminando: "que las mencionadas quiebras no dimanarian por debilidad de muros, entibos, ni sustentantes de los expresados Torales por la Robustes que habia observado en los respectibos de cada uno; y que indicaban provenir de los naturales enjugos y desigualdades del terreno en su planta". Echamorro realizó diversas calicatas, concluyendo que"las nominadas quiebras no eran, ni podian ser de ruina ni que la gravedad del simborio era Capaz de abrumar los torales ni el citado Cruzero"y que "los citados torales segun su diametro, y elevacion no solo no estan escasos de entibo, sino es que tienen mas que lo regular", achacando las quiebras a la desigualdad de la dureza del terreno, "cuio defecto es uno de los tres principales porque se gretean los edificios segun Vitrubio en su libro primero".

No habiendo encontrado motivo alguno para la demolición del cuerpo de luces, el maestro pasó a dar el remedio para los daños aparecidos, "y es que debajo de cada Arco botal, y contra los mismos postes que se han desplomado, se construya otro de pie y medio de rosca la que se labrará con Yeso mesclado con arena en iguales partes y delgados tendeles". Dichos arcos"se formaran en la misma altura que lo estan sus correspondientes opuestos, y despues se masisara su espacio de labor de ladrillo sentados en Cal y Arena en tendeles delgados a fin del mas breve enjugo" ${ }^{64}$ En definitiva, José Echamorro prescribía la solución propuesta desde el primer momento por los maestros de Écija, valorando las reparaciones en 2.500 reales de vellón.

El 13 de septiembre de 1794, el Procurador mayor aceptó el dictamen de Echamorro, solicitando al Provisor su licencia para acometer la reparación.

De esta manera fue como surgieron en la obra de Peñaflor las diferencias entre Rosales y Echamorro, al dar este por buena la solución de los maestros Salazar y Caballero para la reparación de los

63 AGAS, Justicia, Pleitos ordinarios, Leg. 10534, F. 214r bis-219v.

64 Ibídem, F. 233r-244v. 
arcos y pilares torales de la iglesia de Peñaflor y detener su desplome, descartando el derribo del cuerpo de luces, vehementemente propugnado por el maestro mayor diocesano.

Dichas diferencias devendrían en abierta enemistad a partir de octubre de ese mismo año, cuando Echamorro fue nombrado por el procurador mayor de los Sres. Deán y Cabildo, "para calificar si son o no de Rigorosa necesidad" las obras de reconstrucción de las portadas prescritas por Rosales en la utrerana parroquial de Santa María de la Mesa. Discrepando de las condiciones de Rosales, el maestro carmonense propuso las suyas, más económicas. ${ }^{65}$

Sin embargo, las obras al frente de las cuales estaba Echamorro como maestro supervisor desde el 1 de febrero de 1795, serían denunciadas por el procurador mayor de fábricas por el exceso de gastos superfluos, solicitando el 5 de septiembre la visita de los maestros mayores de albañilería y carpintería del arzobispado en presencia de Echamorro. ${ }^{66}$

Fernando Rosales y el carpintero Agustín Trujillo presentan sus informes once días más tarde, confirmando que la capilla bautismal está rematada. En cuanto a las portadas, están casi finalizadas, habiéndose construido con mucho más coste de materiales y molduras de lo previsto en las condiciones. Faltaba por rematar sus dos últimos cuerpos, la sacristía, la capilla sacramental y los porches o lonjas, siendo ya difícil retocar lo ejecutado por Echamorro, a pesar de lo cual el procurador mayor de fábricas solicitó se continuase la obra con arreglo al parecer de Rosales y Trujillo. ${ }^{67}$

El 16 de noviembre de 1795, José Echamorro, que se titulaba "arquitecto mayor de la ciudad de Sevilla", respondió a las acusaciones de excesos de Rosales y Trujillo. Declaraba haberse ocupado solamente de las portadas y los porches, ya que el resto de las obras las dirigía Rosales, quien se excedió sobremanera en el gasto de la obra de la capilla bautismal. Defendía lo ejecutado en las portadas, criticando el diseño anterior de Rosales, quien "mas bien haze los oficios de un litigante (como el Mayordomo de fabrica) que el de un facultatibo Ymparcial, por eso no esplica las Cosas con Cenzilles y Candor porque en este punto no peca de ygnorante (...) y en concluzion llama excesos a lo que ay echo por

\footnotetext{
65 Ibídem, F. 74r-78r.

66 Ibídem, F. 87r-v.

67 Ibídem, F. 84r-94r.
} 
solo no haverlo proyectado el referido Maestro".Y afirma que:“Sin duda el ya citado Rozales a tenido en laVizita que acaba de hazer a la nominada Yglecia y sus obras el mismo tino que tubo a la que hizo en la Yglecia de Peñaflor agregandole a esta algun espiritu de Venganza que deben desterrar los hombres de vien y Verdaderos facultatibos", tachando de "despreciable"la declaración de Trujillo. ${ }^{68}$

La disputa dialéctica, que no la enemistad entre Rosales y Echamorro, quedó ahí y el 22 de enero de 1796 el alarife Francisco Romero informaba que las portadas estaban concluidas"y pintadas de Cal de moron y ocle, asi por el estilo de las Puertas de esta Ciudad Macarena y Arenal" ${ }^{69}$

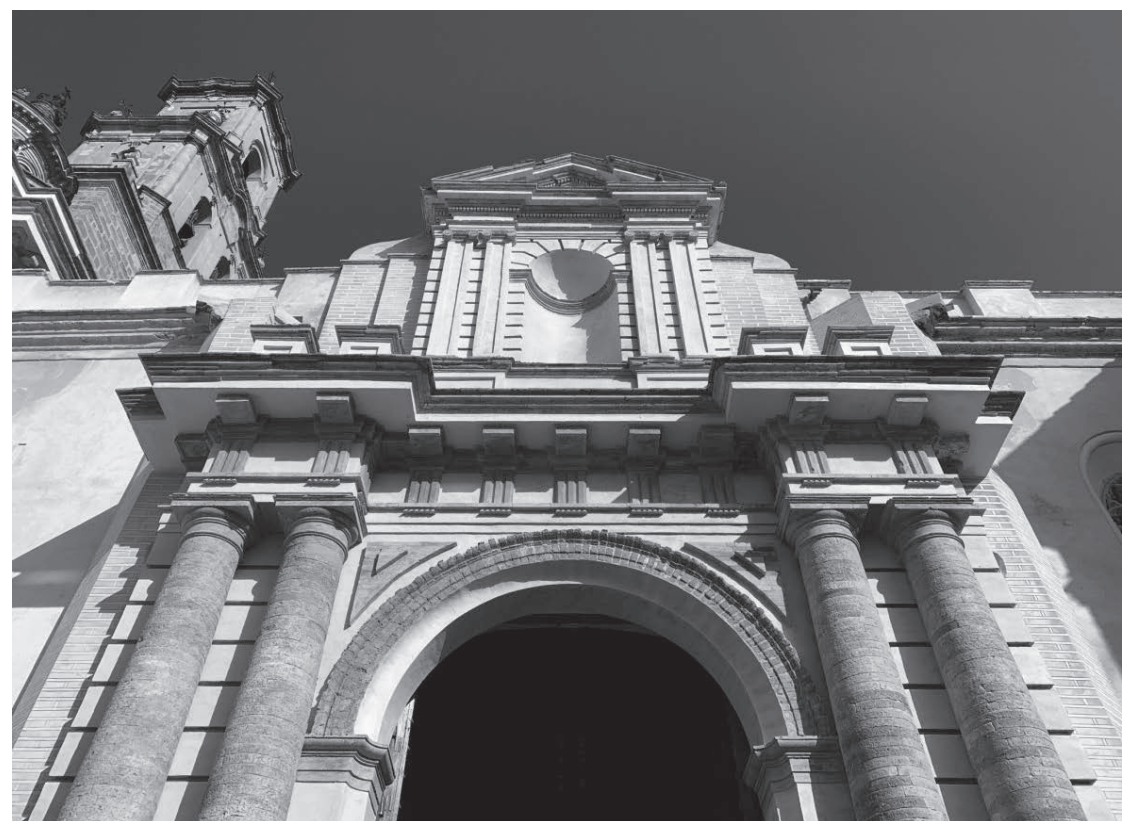

Figura 7. Portada de la epístola de Santa María de la Mesa, Utrera (1795), objeto de una de las polémicas entre Fernando Rosales y José Echamorro. Fotografía del autor.

8 Ibídem, F. 117r-131v.

69 Ibídem, F. 141r-144v. A la polémica se uniría Félix Caraza, "único" arquitecto mayor de la ciudad de Sevilla, que el 26 de junio presentó informe denunciando la usurpación del título por parte de Echamorro, al que califica de "maestro albañil". Ibídem, F. 223r-232r. Al respecto de la disputa entre Rosales y Echamorro, cf. Ollero Lobato, Cultura artística y arquitectura, 390-391. 


\section{LA CONCEPCIÓN DE HUELVA, LA ESCUELA DE CRISTO EN SEVILLA Y SANTA MARÍA DE ÉCIJA}

A Fernando Rosales se debe la gran reforma de la parroquia onubense de La Concepción, llevada a cabo entre 1794 y 1798, en la que se construyeron los arcos de los intercolumnios, el apilastrado de pilares y muros, las falsas bóvedas perdidas en 1936, la nueva capilla del Sagrario y la portada de la calle del Hospital (actual Méndez Núñez), obras finalizadas por Santiago de la Llosa el 17 de agosto de $1798 .^{70}$

Rosales alcanzaría oficialmente el puesto de maestro mayor del arzobispado de Sevilla en 1795, teniendo lugar su nombramiento en la sesión del cabildo catedral del 3 de febrero. ${ }^{71}$ Este año se trasladaría, junto con su familia, a la collación de San Miguel, donde permanecería el resto de su vida.

Antes de finalizar el siglo, concretamente en 1796, el maestro proyectaría uno de sus escasos edificios religiosos de nueva planta en la capital hispalense: se trata del oratorio de la Escuela de Cristo, de amplia volumetría y hermosas proporciones, aunque de reducida planta; escondido entre el laberinto de callejuelas y callejones del barrio de Santa Cruz, a través de uno de ellos se accede al patio donde tiene su entrada la capilla. En la portada, característica de Rosales, dos pilastras dóricas con entablamento de triglifos y metopas flanquean un vano de medio punto. Un frontón recto partido encuadra a su vez a otro central triangular más pequeño y elevado, del que pende un pinjante, sobresaliendo del conjunto en altura los típicos tres remates. Las fachadas del oratorio están recubiertas con esgrafiados"con motivos serlianos, atestiguando el influjo de los modelos renacentistas estudiados en la tratadística tradicional". ${ }^{72}$ Las obras finalizarían en 1801.

70 Sobre la historia constructiva del templo, cf. Manuel José de Lara Ródenas, Biografía de una iglesia, la parroquia de la Concepción de Huelva, Huelva, Colegio Oficial de Arquitectos de Huelva, 2005.

71 ACS, Libro de Actas Capitulares de 1795, sesión de 3.Feb. Cf. SANCho Corbacho, Arquitectura barroca sevillana, 263.

72 Cf. SAncho Corbacho, Arquitectura barroca sevillana, 263. También cf. Ollero Lobato, Cultura artística y arquitectura, 389. Dichos esgrafiados son similares a los trazados por Fernando Rosales sobre los muros de la sevillana iglesia de San Bartolomé, cuyas obras finalizaron en 1796. 
En esta revisión de la vida y obra de Fernando Rosales, en la que se han presentado diversas intervenciones hasta ahora desconocidas, se documenta a comienzos del siglo XIX otra realización inédita del maestro: el 22 de septiembre de 1791 Antonio de Figueroa informaba que las obras del cuerpo de iglesia y capilla sacramental del ecijano templo de Santa María, por él proyectadas, estaban prácticamente concluidas, ${ }^{73}$ dando el 30 de abril de 1795 Fernando Rosales el cumplido. ${ }^{74}$ Pero no iba a ser esta la última intervención de Rosales en Santa María, cuya fábrica avisaba el 21 de enero de 1804 que hacía unos días se habían advertido grietas y desplomo en la pared de la nave que daba a la calle (nave de la epístola), solicitando la visita del maestro mayor. ${ }^{75}$ El 13 de octubre de 1805, el maestro mayor declara que"advirtio varias quiebras en las bovedas asi de las menores como la que cubre la nave mayor y arcos que dividen dichas bovedas, en particular los que hacen de botales en las menores, todo lo mas dimanado de asiento de obra, y solo en la dicha Guardera de la Epistola es donde se advierte algun desplomo a la Calle", por lo que por seguridad prescribe que "es urgente construirle unos botales a la parte exterior dejando diafana y de uso la Calle como y está, tomando un poco de terreno del sitio de la Casa opuesta hasta para cinco en forma de arco, con dos tercias de grueso y dos tercias de dobela, dandole a los muros de paredes tres y media varas de longitud intruso en el sitio de dicha casa o quando menos la mitad del ancho de la Calle, quedando en forma de medio arco que sus claves bajen vara y media quando menos por bajo del buelo de los tejados", valorando las obras en 32.000 reales. $^{76}$

Para detener el desplome de la gualdera de la epístola, Rosales proyecta una sencilla, pero ingeniosa y estética solución, consistente en disponer dos contrafuertes en forma de arbotantes a la altura de la portada de ese lado, flanqueándola, cubriendo el conjunto con un tejado a dos aguas con pretil, que queda perfectamente integrado como si fuera un porche realizado con la obra inicial de la iglesia. En el intradós se dispone una bóveda de arista.

\footnotetext{
AGAS, Justicia, Pleitos ordinarios, Leg. 10691, F. 565r-566r.

Ibídem, F. 568r-569r.

AGAS, Justicia, Pleitos ordinarios, Leg. 10319, F. 1r-v.

Ibídem, F. 3r-4v.
} 
En su declaración del 21 de octubre de $1808,{ }^{77}$ realizada tras una nueva visita a la iglesia para "reconocer el estado de la Obra de la $\mathrm{Yg}^{\mathrm{a}}$. Parroquial de Sta. Maria, modo y forma de reparar la Portada de la guardera donde se han construido los estrivos: como asimismo la composicion o reparacion que necesitan los cubiertos de Colgadizos de los quatro Angulos de Corredores del Patio de Sacristia, colecturia y demas Oficinas de dicha $\mathrm{Yg}^{\mathrm{a}}$. modo y forma de su construccion, y costo a que ascenderá", el maestro Rosales declaró que había encontrado "hechos los Arcos botales y el estrivo proyectado a lo exterior, rematado uno y otro como corresponde o quedaron proyectados; y de acuerdo con el Maestro Mayor de aquella Ciudad, con todas las estrivaciones intrusas en el sitio que se tomó en la linea opuesta, y labrada su Cerca hasta la altura que corresponde; todo bien construido, con la calidad que requiere, para conseguir la subsistencia de esta guardera, y demas de lo interior de esta $\mathrm{Yg}^{\mathrm{a}}$. que apoya o estriva contra ella"; dando además las instrucciones para modificar la portada lateral, labrada por Figueroa, a fin de resolver el porche cubierto:

Por lo que hace a la Portada que está a lo esterior de la dicha guardera entre los dos Arcos botales necesita quitar todo el cuerpo segundo y baxar su desmonte hasta la Clave de la puerta (...) y justamente este segundo cuerpo quedaria oculto: la mitad de este con la misma boveda que ultimamemte fue determinada (...) por lo que es indispensable su derribo hasta dicho sitio (...) Al mismo tiempo se formará a dicha portada para su Coronacion solo un frontis orisontal y sin movimiento alguno, y en disposicion que pase la boveda en su altura por su final o angulo. La citada vobeda debe ser de tabique doble empalomado y solada por cima en forma de azotea...

77 Ibídem, F. 14r-15r. 


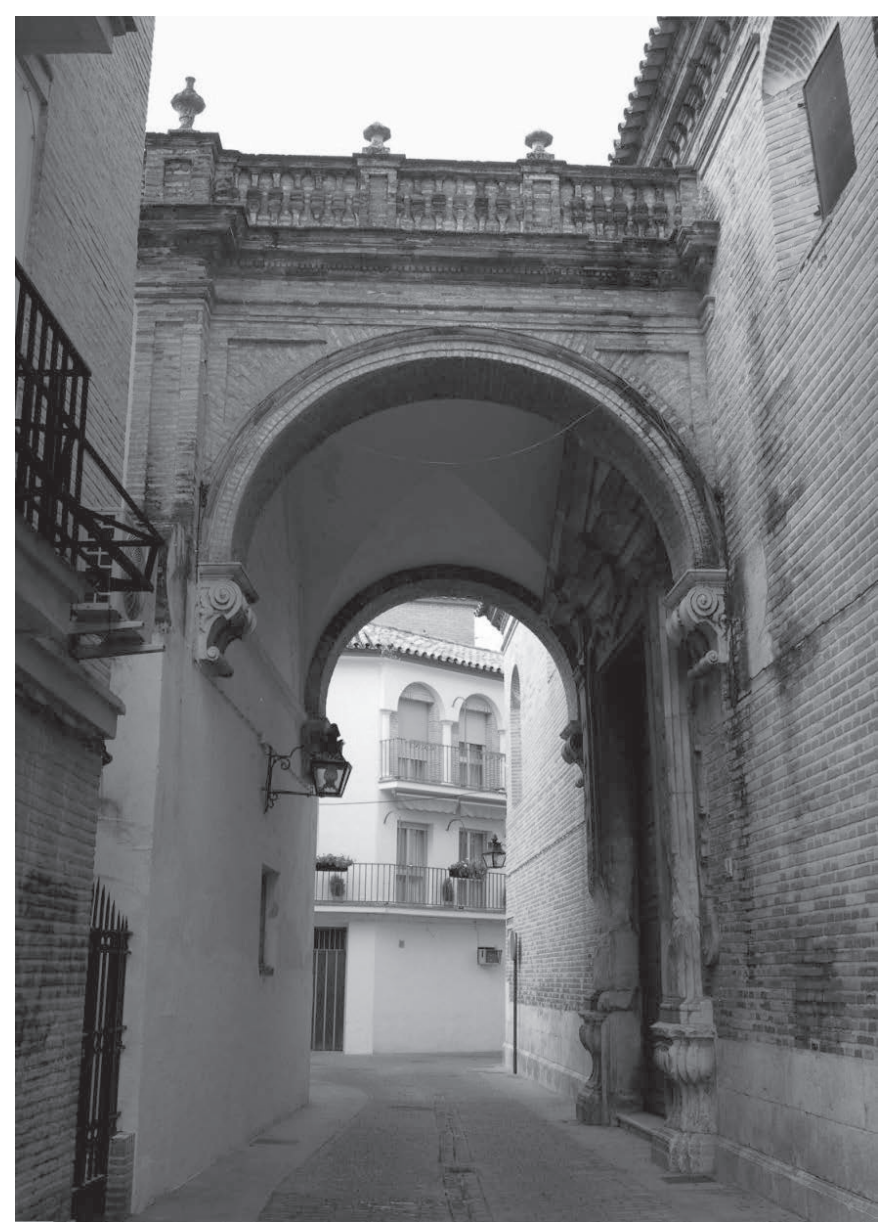

Figura 8. Porche cubierto sobre la portada lateral de la epístola, en la iglesia ecijana de Santa María, proyectado en 1805 por Rosales para evitar el desplome de la gualdera. Fotografía del autor.

Es decir, hubo que suprimir el segundo cuerpo de la portada de Figueroa, sustituyéndolo por un frontón triangular, tal y como se puede ver hoy día. Sin embargo, la antigua casa frontera a la portada ya no existe, subsistiendo los machones de los arbotantes unidos por un lienzo de muro. ${ }^{78}$

78 Sobre la construcción de la iglesia de Santa María, cf. José Manuel Higuera MelÉNDEZ, "Las intervenciones en Écija del maestro mayor sevillano Antonio de 
En la fecha de esta visita, 1808, Fernando Rosales, que permanecería soltero toda su vida, ya residía en una casa de la calle de las Palmas (actual Jesús del Gran Poder) esquina a calle Baena (actual Padre Tarín), adquirida el año anterior. ${ }^{79}$

\section{OTRAS INTERVENCIONES. ARQUITECTURA CIVIL Y LA DIRECCIÓN DE LA ESCUELA DE LAS TRES NOBLES ARTES}

Otras notorias intervenciones diocesanas no citadas de Fernando Rosales como proyectista y director de obras fueron: condiciones para ejecutar el proyecto de Figueroa de la iglesia de Alosno (1785); informe sobre las puertas de Jerez (1785, con Ginés de San Martín y José Camino); condiciones para reedificar la parroquial de Arahal (1785); obras para eliminar humedades en la parroquial de Morón de la Frontera (1786-1787); condiciones para finalizar la iglesia de Alájar (1787); ${ }^{80}$ reforma y ampliación de la iglesia de Villarrasa (1788-1794,

Figueroa (1733-1793): una obligada puesta al día", Isidorianum 49 (2016) 107-158: https://doi.org/10.46543/ISID.1625.1006.

79 AHPS, FPN, Of. 19, Libro $3^{\circ}$ de 1807, F. 713r-767r, Sign. 13227. Inédito.Venta de casa propiedad del Cabildo catedral a D. Fernando Rosales. Se trata de "Casas en la Calle de las Palmas num ${ }^{\circ}$ quatro de Gobierno (...) su area superficial doscientas diez y seis Varas quadradas su estado ultima vida linda por su derecha con la Callejuela de Baena y por su hisquierda con otras del Monasterio de $\mathrm{S}^{n}$. Clemente...". El 9.May.1807 se remataron en 22.000 reales de vellón por D. Diego Juárez, "de orden y para D. Fernando Rosales vecino de esta ciudad". D. Diego Juárez era oficial del Real Archivo de Indias y su cuñado, al estar casado con su hermana Joaquina. D. Diego Juárez y Joaquina Rosales tuvieron un hijo, Francisco de Paula, del cual Fernando Rosales sería nombrado "curador ad litem" el 14.Ene.1822, tras fallecer su cuñado.

80 Posteriormente, en julio de 1788, Antonio de Figueroa emitiría otro informe para proseguir las obras, que se encontraban detenidas. Refutando las aportaciones anteriores sobre el edificio, que atribuyen a Pedro de Silva sus trazas (cf. Teodoro Falcón, Pedro de Silva, arquitecto andaluz del siglo XVIII, Sevilla, Diputación de Sevilla, 1979, 39-40; también cf. Manuel Bendala Galán - Antonio Collantes de Terán Sánchez - Teodoro Falcón Márquez - Alfonso Jiménez Martín (eds.), Catálogo Monumental de España. Provincia de Huelva. I: Alájar, Huelva, Consejería de Cultura de la Junta de Andalucía, 1992, 45-88), se aporta aquí por primera vez la noticia de que la iglesia parroquial de Alájar fue con seguridad construida en base a la planta de tres naves presentada en octubre de 1774 por Tomás Bottani, asimismo maestro ejecutor hasta su paralización. El proyecto de Silva de 12.Ago.1773 fue rechazado y devuelto. La bendición del templo tuvo lugar 
con Figueroa); condiciones para ejecutar las obras del templo de Galaroza (1790-1796); ${ }^{81}$ condiciones para obras en la parroquial de Chucena (1791); reforma y ampliación de la iglesia de Paymogo (1791-1796, con Figueroa); condiciones y plano para cubrir y finalizar el templo de Chipiona (1792); reparaciones de cubiertas y reforma de bóvedas y cuerpo de iglesia en Fuenteheridos (1792-1796); ${ }^{82}$ ampliación de la iglesia de Puerto Serrano (1793-1798); reparaciones y reformas en el templo de El Garrobo (1793-1801); ampliación de la Sala de Rentas de la catedral de Sevilla (1805); y renovación de cubiertas y cuerpo de campanas de la iglesia de La Rinconada (18161818, con su hermano Juan José).

En su calidad de maestro mayor del arzobispado, además de los referidos proyectos y obras, Fernando Rosales también llevó a cabo numerosos reconocimientos de casas y solares pertenecientes a las distintas fábricas parroquiales, ${ }^{83}$ así como el diseño de retablos y otros elementos litúrgicos. ${ }^{84} \mathrm{Y}$, como es lógico, también atendió los

el 14.Ago.1792, sin estar concluida la torre, y el año siguiente continuaban las obras, dirigidas por Francisco Díaz Pinto. ADH, Justicia, Alájar, 1, Ordinarios, Clase $2^{\mathrm{a}}, \mathrm{n}^{\circ} 1-3$, Años 1727-1770.

81 Entre 1790-1791 siguiendo el proyecto de 1789 de Antonio de Figueroa. A partir de 1794, según el de la Real Academia. El 8.Abr.1802 su hermano Juan José daría el cumplido de las obras.

82 Se aporta aquí la noticia de que la iglesia de Fuenteheridos debe sin duda su apariencia actual a dicha intervención de Rosales, que realizó la media naranja y su cubierta, amplió la capilla mayor y reformó la nave y el teórico crucero, introduciendo los cuatro rotundos pilares semicirculares de refuerzo que hoy lo limitan. El templo se había atribuido a la intervención llevada a cabo por Pedro de Silva entre 1768 y 1775 (cf. FALCÓN, Pedro de Silva, 42-43, 58); sin embargo, su estado de ruina requirió de la citada reforma definitiva de Rosales. ADH, Fuenteheridos, Justicia, Clase 2a, Leg. 236.

83 La mayoría de ellos realizados con Francisco del Valle o con Agustín Trujillo, maestros mayores de carpintería. Al respecto, cf. Francisco S. Ros GonZÁlez, Noticias de Escultura (1781-1800), (Fuentes para la historia del arte andaluz XIV), Sevilla, Guadalquivir ediciones, 1999.

84 Como los diseños del monumento para la carmonense iglesia parroquial de S. Pedro (1788, ibídem, 880-881) y del retablo de S. Antonio para el nuevo templo de Algodonales (1786, cf. Falcón Márquez, Iglesias de la Sierra de Cádiz, 170), donde era reconocido como"de particular habilidad en divujos". En 1818 es desestimada por parte de la Academia su participación en la realización del retablo mayor para el convento sevillano de S. Agustín. Cf. Carmen Sotos SerRano, "El retablo de San Agustín de Sevilla", Archivo Español de Arte 45 (1972) 287-295. 
encargos de particulares para el reconocimiento y valoración de sus propiedades. $^{85}$

En cuanto a la arquitectura civil, faceta sin duda empequeñecida por su ingente labor a las órdenes del arzobispado hispalense, al que dedicó cuarenta y seis años de su vida, ${ }^{86}$ hay que dejar constancia de numerosos proyectos de viviendas realizados por el maestro para particulares, algunas de las cuales, que han resistido los embates del tiempo y las modas, se identifican y presentan aquí por vez primera. ${ }^{87}$ Como por ejemplo, el proyecto de vivienda de tres plantas en la antigua calle Bayona (actual Federico Sánchez Bedoya, n 5), datado en 1804, de estilizada fachada, cuya planta baja ha sido alterada por la apertura de un portalón para cochera donde antes había una ventana. Destacan la conformación del balcón, bajo el cual aparecen dos ménsulas bulbosas con sus características cornisas con dentículos, y el rotundo cornisamento de remate. ${ }^{88}$

85 Entre ellos, presentado en el Apéndice Documental, el de $\mathrm{D}^{\mathrm{a}}$. M $\mathrm{M}^{\mathrm{a}}$ Josefa Morón en relación con su casa, que curiosamente era la misma que construyó y habitó durante años Antonio de Figueroa.

86 Fernando Rosales mantuvo hasta el fin de sus días el título de maestro mayor de la diócesis: "En 7 de Octubre se despachó tit ${ }^{\circ}$ de Maestro Mayor de Alarife de las Obras de Quartas Partes en lugar y por muerte de D. Fernando Rosales a D. Antonio Diaz Gracia" (AGAS, Medios de información, Leg.16432, F. 97r, 7.Oct.1830).

87 En Ollero Lobato, Cultura artística y arquitectura, 294 y 400-401, se cita el proyecto de la vivienda en calle Bayona. Sin embargo, ni se identifica dicha calle con la actual ni el edificio al que corresponde, aportaciones que se hacen aquí. Entre 1802 y 1820, hay registradas en el AHMS ciento veintitrés solicitudes de licencias de obras en las que consta Fernando Rosales como arquitecto.

88 AHMS, C. A. Abecedario de Calles, Expedientes de licencias de obras, Años 1789-1877. Calle Bayona, año 1804. Cf. Francisco Collantes de Terán - Luis GómeZ EsTERn, Arquitectura civil sevillana, Sevilla, Ayuntamiento de Sevilla, 1984, 171: "Casa del siglo XVIII, que consta de tres plantas". 


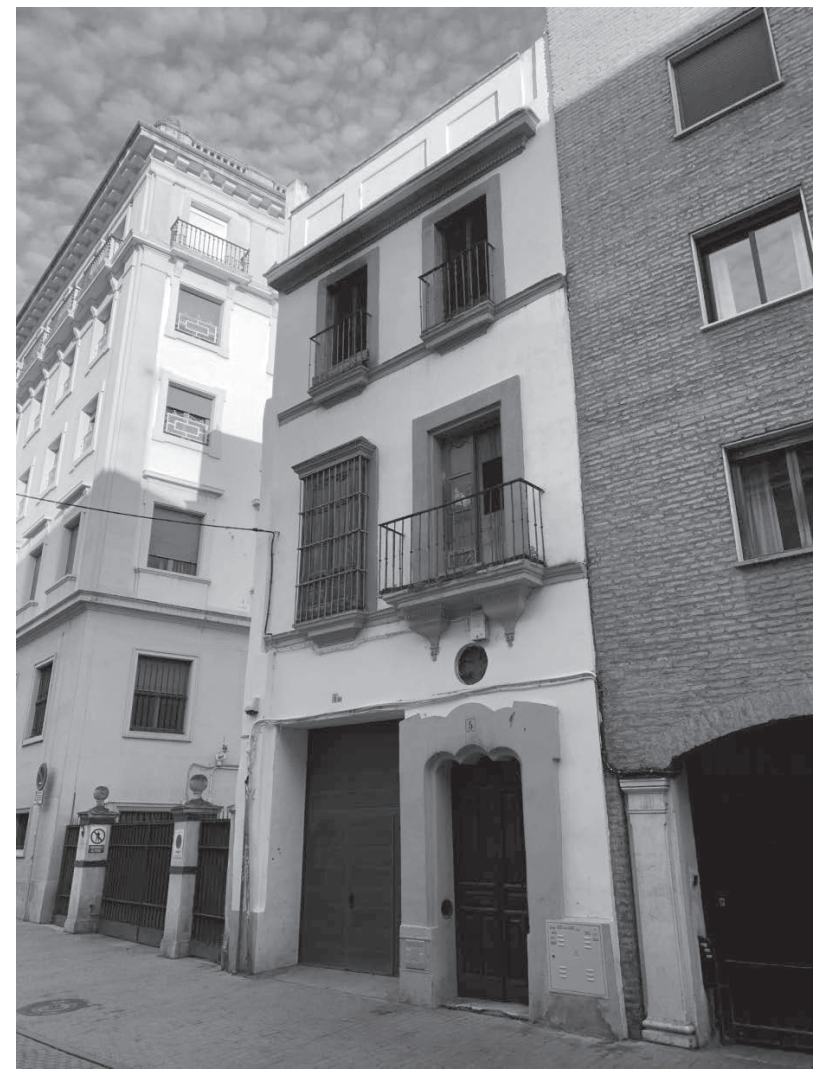

Figura 9. Aspecto actual de la vivienda sita en C/ Federico Sánchez Bedoya, 5. Fernando Rosales, 1804. Fotografía del autor.

También es obra de Fernando Rosales la vivienda $\mathrm{n}^{\circ} 31$ de la calle Abades, de tres plantas de altura. La solicitud de licencia de obra tiene fecha de 30 de agosto de 1810, apareciendo en el dintel de su sencilla y elegante portada resaltada la leyenda "SE ACABO AÑO DE 1811", orlada por dos paños esgrafiados. Sobre la puerta, la cornisa con dentículos vuela en su tramo central para formar el balcón, que se apoya sobre una repisa de formas curvas característica de Rosales. ${ }^{89}$ La fachada de la contigua vivienda $n^{\circ} 29$ guarda gran

89 AHMS, C. A. Abecedario de Calles, Expedientes de licencias de obras, Años 1789-1877. Calle Abades, años 1810, 1811. Respecto del n 31, propiedad de D. Joaquín Moreno, Rosales presenta solicitud de licencia para "arreglar la fachada de la calle a Arte", adjuntando el nuevo alzado, que coincide con la fachada 
semejanza con la anterior, por lo que posiblemente sea también obra del maestro mayor.

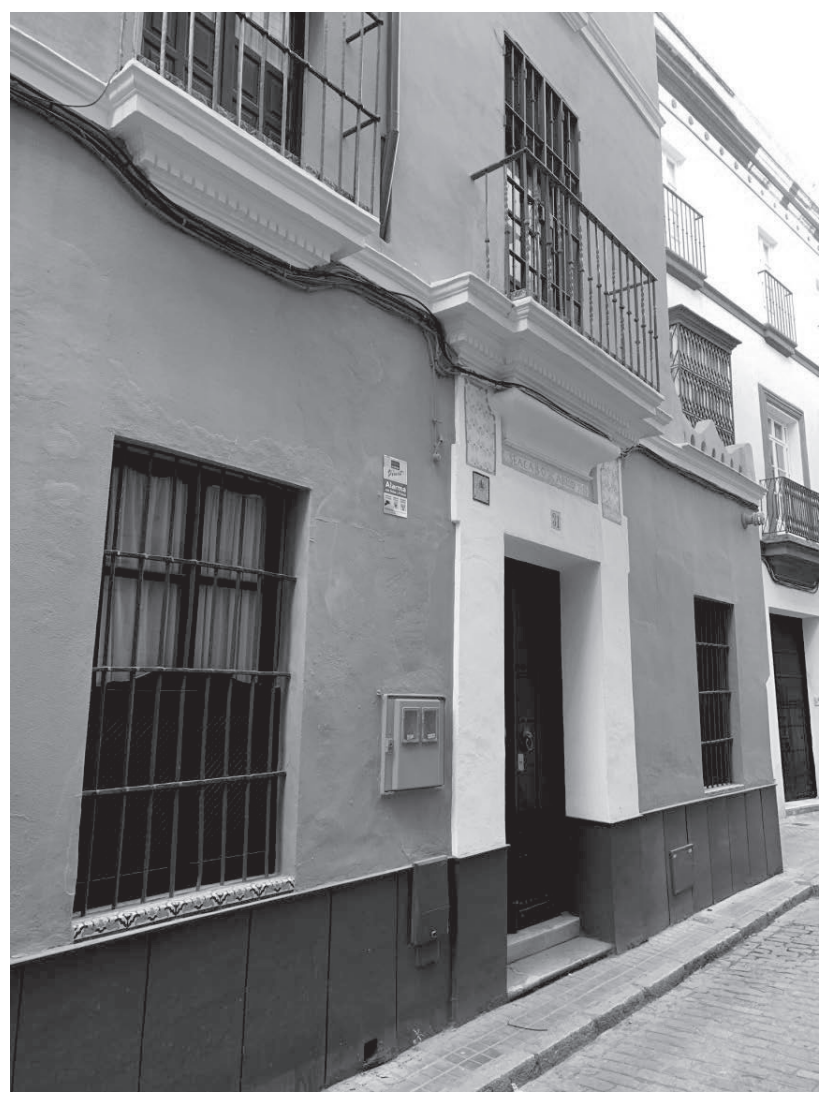

Figura 10. Detalle de la vivienda sita en C/ Abades, 31. Fernando Rosales, 1811. Fotografía del autor.

Además de haber sido alumno en la Escuela de las Tres Nobles Artes de Sevilla, Rosales ocupó desde el 6 de enero de 1801 el cargo de Teniente de Arquitectura de dicha institución académica, siendo nombrado el 30 de noviembre de 1810 Director de Arquitectura

actual (Expte. 1/1810). En 1811 solicita ejecutar un nuevo alcantarillado para la vivienda (Expte. 1/1811). Cf. Collantes de Terán - Gómez Estern, Arquitectura cioil, 11: "Casa gemela del número 29". № 29: "Casa del siglo XVIII, de tres plantas, con la cornisa del balcón muy volada". 
interino, en sustitución de Francisco de Paula Guerrero, plaza que ostentaría hasta el 20 de octubre de 1814, en que este se reintegró. ${ }^{90}$ Fernando Rosales sería nombrado Director de Arquitectura titular el 25 de abril de 1820, hasta que el 15 de marzo de 1829 reclamó su jubilación. ${ }^{91} \mathrm{Y}$ a pesar de estar tan ligado a la entidad académica, fueron rechazados, como ya se vio, todos sus proyectos enviados a la Comisión de Arquitectura de la Real Academia de Bellas Artes de San Fernando, que lo consideraba un mero maestro albañil.

Entre los maestros de la diócesis con los que Rosales tenía buena relación destaca Agustín Trujillo, maestro mayor de carpintería a partir de finales de la década de 1780, quien lo nombró albacea testamentario, juntamente con D. Francisco Velilla y el también maestro mayor de albañilería Santiago de la Llosa.

Fernando Rosales falleció el 15 de febrero de 1830, pobre y sin hacer testamento a pesar de haber sido uno de los más renombrados, activos y prolíficos maestros mayores de obras del arzobispado, y sin duda el más longevo en el cargo, celebrándose su funeral el día siguiente en la parroquia de San Miguel. ${ }^{92}$

90 Como Director de Arquitectura cobraba Rosales 200 ducados (2.200 reales) anuales. Durante este período falleció su madre, enterrada en S. Miguel. Cf. APSMMS-PSMS, Libro 5 de entierros 1750-1814, F. 278r. Inédito:"En diez y siete de Septiembre de mil ochocientos doce años los Beneficiados de esta Parroquial de ${ }^{\mathrm{n}}$. Miguel de Sevilla dieron en ella sepultura Ecc ${ }^{a}$. al Cadaver de $\mathrm{D}^{\mathrm{a}}$. Ynes Ramos que falleció en diez y seis de este mismo mes y año recivió los Stos. Sacramentos y no texto". Dos años antes había fallecido su padre, el alarife Alejandro Rosales. Cf. APSMMS-PSMS, Libro 5 de entierros 1750-1814, F. 269v. Inédito: "En catorce de febrero de mil ochocientos diez años los Benef ${ }^{\text {dos }}$ de la Parroquial de S. Miguel dieron en ella sepultura Ecc ${ }^{\mathrm{a}}$ al cadaver de $\mathrm{D}^{\mathrm{n}}$ Alexandro Rosales marido que fue de $\mathrm{D}^{\mathrm{a}}$.Ynes Ramos, recivió los Stos Sacramentos y fallecio en trece del mismo mes y Año".

91 Cf. Muro Orejón, Apuntes para la historia de la Academia de Bellas Artes de Sevilla, 153.

92 Cf.APSMMS-PSMS, Libro 6 de entierros 1815-1847, F. 62r. Inédito. Partida parroquial de defunción de Fernando Rosales: "En diez y seis de febrero de mil ochocientos treinta años el Cura y Clero de esta Parroquial de $S^{n}$. Miguel Arcangel de Sevilla condujeron al Cementerio publico el Cadaver de D ${ }^{\mathrm{n}}$. Fernando Rosales, de estado Soltero, de edad setenta y cuatro años. Recivió los Stos. Sacramentos, y no testó por ser Pobre: fallecio en quince de febrero de dicho año". 


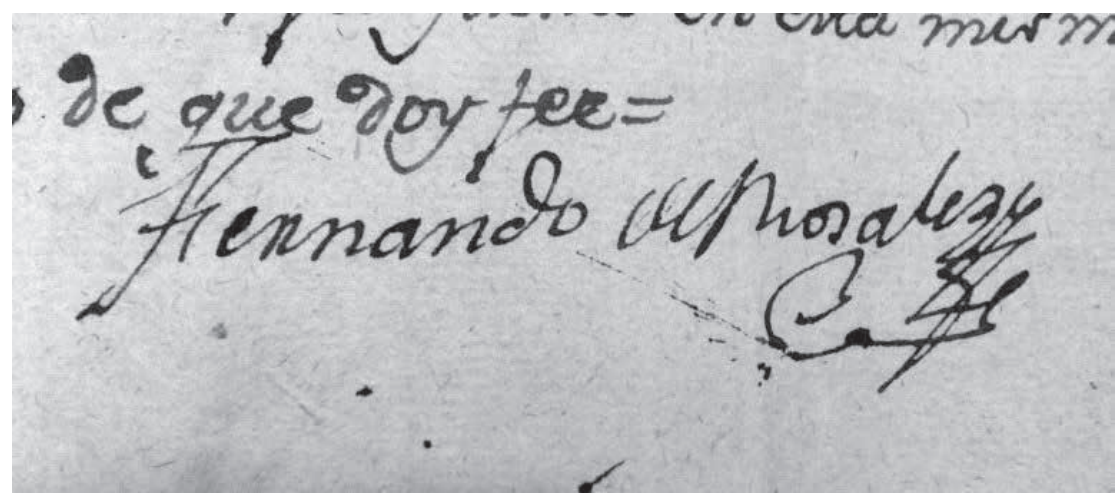

Figura 11. Firma de Fernando Rosales (1795). Fotografía del autor.

\section{CONCLUSIONES}

Como se expuso al principio, el objetivo de este trabajo era incrementar el conocimiento existente sobre la figura del arquitecto Fernando Rosales, en sus facetas tanto humana como artístico-laboral. El interés de dicha investigación está suficientemente justificado, puesto que se trata de uno de los más fecundos y notables profesionales de su época en Sevilla. Tanto es así que, de los maestros mayores del arzobispado nombrados a lo largo del siglo xVIII, fue el que ostentó oficialmente el cargo durante más tiempo (46 años). ${ }^{93}$

De esta manera, por lo que respecta al apartado biográfico, se han sacado a la luz sus orígenes familiares y se ha formulado una plausible hipótesis sobre la fecha de su nacimiento y bautizo en Santa Marina, cuya partida se ha perdido, habiéndose documentado su fallecimiento y entierro, junto con los de sus padres, en la desaparecida iglesia de San Miguel. Se ha dado a conocer su entorno familiar, entre cuyos miembros se hallaba su hermano menor Juan José, quien también alcanzaría la maestría mayor de la Iglesia de Sevilla. Ha quedado documentado el periplo seguido a lo largo de su vida por diferentes collaciones de la ciudad junto con su familia, a la que

93 Piénsese por ejemplo que Diego A. Díaz lo hizo durante 36 años (1705-1741), aunque de forma discontinua por sus problemas de salud; Pedro de Silva, 25 años (1757-1782); Ambrosio de Figueroa, 13 años (1762-1775); Antonio de Figueroa, 17 años (1776-1793); Santiago de la Llosa, 41 años (1794-1835); y José Álvarez, nombrado por el Deán y Cabildo, trabajó durante 33 años para la diócesis (1767-1800). 
siempre estuvo muy unido por el hecho de haber permanecido soltero, circunstancia que también se desconocía. Especialmente estrecha fue su relación con su hermana Joaquina, hasta el punto de ser nombrado "curador ad litem" de su sobrino Francisco de Paula tras fallecer su cuñado. En cuanto a su círculo de amistades, parece claro que lo formaron sus propios colegas de profesión, como Antonio de Figueroa, que actuaría como su mentor en la maestría mayor del arzobispado, Santiago de la Llosa, también maestro mayor de obras diocesano, y Agustín Trujillo, que lo era de carpintería. De igual modo se ha profundizado en las desavenencias que mantuvo con José Echamorro, dando a conocer por primera vez los informes evacuados por ambos alarifes en relación con la iglesia de Peñaflor. Finalmente, se han aportado datos sobre los escasos bienes que poseía a su fallecimiento, reducidos a la posesión de una casa en la calle de las Palmas (actual Jesús del Gran Poder).

En cuanto al aspecto profesional, se han repasado algunos datos ya conocidos del arquitecto, sin los cuales no podría entenderse el devenir de su carrera, como su formación en la Academia sevillana, de la que llegó a ser director; a la vez que su pertenencia constante al gremio de albañilería de la ciudad, en el cual ostentó diversos cargos. Partiendo de ahí, y debidamente contextualizadas en el desarrollo cronológico de sus realizaciones, se han añadido al listado de obras conocidas varias interesantes intervenciones inéditas. Tal es el caso de la parroquial de Villanueva de las Cruces, atribuida hasta ahora a Antonio de Figueroa; la rehabilitación en Carmona de la antigua iglesia del Colegio de San Teodomiro para ubicar en ella la parroquia de Ntro. Señor S. Salvador; la novedosa reforma de la iglesia de Valencina; las importantes obras de ampliación y rehabilitación del templo parroquial de Fuenteheridos, modificando el aspecto interno y la volumetría exterior del edificio construido años atrás por Pedro de Silva; y la realización del elegante porche en la portada de la epístola de la monumental iglesia ecijana de Santa María, ingeniosa y estética solución constructiva para detener el desplome de la gualdera del templo. Y como añadido a las antedichas realizaciones inéditas, ha quedado formulada la atribución tanto de la torre del templo de San Martín de Tours de Bollullos de la Mitación como del resto de las obras de finales del XVIII que afectaron a la iglesia.

Fuera del ámbito de su trabajo al servicio de la diócesis, son numerosos sus informes de reconocimientos de casas y solares, así 
como sus proyectos destinados a la arquitectura doméstica o civil, de los cuales se han aportado varios ejemplos inéditos.

Fernando Rosales ha sido tradicionalmente relegado a un segundo plano por la historiografía del arte, ya que otros maestros que lo precedieron en el cargo de arquitecto al servicio de la Iglesia, como Pedro de San Martín, Pedro de Silva, Ambrosio y Antonio de Figueroa y José Álvarez, acometieron la inmensa mayoría de los proyectos de renovación de templos tras el terremoto de Lisboa, realizándolos de nueva planta; por lo que a nuestro arquitecto le correspondió en principio intervenir en obras de menor entidad. Sin embargo, es preciso poner en valor su obra, en primer lugar porque al pertenecer a la generación posterior de maestros mayores diocesanos, tuvo la oportunidad de acometer importantes reformas en un buen número de los templos construidos por sus predecesores, incluso por los que fueron sus contemporáneos en el cargo algún tiempo, como Antonio de Figueroa y José Álvarez. Así ocurrió por ejemplo en Villanueva de las Cruces, Paradas y San Bartolomé de Sevilla, intervenciones que contaron con la aprobación de sus propios colegas.Y finalmente tampoco hay que desdeñar el hecho de que, por medio de su obra, impregnada de su espíritu académico, Fernando Rosales fue adecuando paulatinamente la persistente estética barroca de los alarifes sevillanos a los nuevos tiempos artísticos, al igual que el nuevo orden jurisdiccional en el que la Academia ejercía la jerarquía arquitectónica se fue imponiendo al ya anacrónico mundo del viejo estamento gremial. 


\title{
APÉNDICE DOCUMENTAL
}

\section{Examen de maestro albañil de Fernando Rosales. Capilla de San Andrés. Sevilla, 31.Mar.1782}

\author{
AHMS, Sec. XVI, Carp. 1663, Caja 174, Doc. 194, F. 235r-v \\ (Al margen): Fernando Rozales
}

En la MN y M L Ciudad de Sevilla a treinta y uno de Marso de mil setecientos ochenta $y$ dos estando en la capilla del Glorioso Apostol $S^{r}$. $S^{n}$. Andres que es de los Maestros del Arte de Alvañileria Bernavé Romero y Manuel Tamayo Alcaldes Alarifes, Antonio de Figueroa y Jph Gonsales examinadores de el nombrados por el Yllmo Cavildo y Regim ${ }^{\text {to }}$ de esta dicha Ciudad parecio presente Fernando Rosales que assi dijo llamarse ser vezino y natural de ella hijo lexitimo de Leandro Rosales y de Ynes Ramos su Muger que es pequeño de cuerpo color trigueño claro pelo castaño ojos pardos serrado de barba con una Zicatriz en la frente y de edad de veinte y siete años y dijo que de quince a esta parte está usando dicho Arte por haverlo aprendido con el referido su Padre que es Maestro de el en esta Ciudad y que lo quiere ejercer por si solo por lo que pidio a los dichos Alcaldes Alarifes y examinadores lo examinen de Maestro; y visto por los susodichos por ante mi el infrascrito ss ${ }^{n o}$. de S.M. de Comiciones de dicho Yllmo. Cavildo y de Alarifes le hicieron muchas preguntas y repreguntas tocantes y pertenecientes al referido Arte $y$ que trasara y modelara con una regla y compas muchas trasas y trasó y modeló todo lo que le fue preguntado y dió buena cuenta y razon de todo ello por lo qual los dichos Alcaldes Alarifes y examinadores de conformidad dijeron que examinaban y examinaron a dicho Fernando Rosales de Maestro del referido Arte de Alvañileria de limpio tosco y cañero y le dieron poder y facultad para que lo pueda usar y ejercer en quanto a lo susodicho asi en esta ciudad de Sevilla como en las demas ciudades Villas y lugares de estos Reynos y señorios de S. M. de cuia parte ruegan y encargan y de la suia piden de merced a los Señores Jueses y Justicias destos Reynos y señorios de S. M. que siendoles mostrada esta Carta de examen o su traslado signado y firmado del infrascrito ss ${ }^{\text {no }}$. haian y tengan por tal Maestro examinado del referido Arte a dicho Fernando Rosales y se lo dejen usar libremente sin le poner embaraso alguno y lo firmaron dichos Alcaldes Alarifes y examinadores de que doy fee $=$

Bernabe Romero

Joseh gonsales

Di la carta de examen dicho dia
Antonio de Figueroa

Manuel Tamayo

Ante mi

Pedro de Vega

Thamariz 


\title{
2. Instancia de Fernando Rosales para optar al cargo de maestro mayor de la ciudad en sustitución de Félix Caraza. Sevilla, 3.abr.1786
}

\author{
AHMS, Sec. 5', Leg. H-1085, Año 1786, Leg. 16, n² 29, F. 7r \\ "Yll"mo. Señor
}

Señor

Fernando Rosales, Vecino de esta Ciudad natural de ella, Mtro. Alarife y Mayor de la Dignidad Arzobispal, de aucencias y enfermedades del Y $l^{m o}$. Cavildo Eclesiastico, Yndividuo de la Escuela de las tres nobles Artes de esta dicha Ciudad, Premiado en oposicion con otros de su Facultad, y actual Alcalde Alarife: con todo el devido respeto a V.S. Y dice que todas sus tareas, aplicacion y desvelo en su adelantamiento en la mayor instruccion de su exercicio o Arte, han sido y son con objeto de ver si puede conseguir tener la distincion de titularse criado de V.S.Y.; lo qual puede mui bien verificarse si su Piedad se digna conferirle el nombramiento de su Arquitecto o Mtro. Mayor de Obras en lugar de $D^{n}$. Felix Carazas, que ha estado exerciendo este encargo; en el que la penetracion de V.S.Y. verá el devido cumplimiento de las obligaciones de Supp ${ }^{\text {te }}$, la justa economia en el manejo y disposicion de las obras que se ofrescan, y que devidamente le hace ver corresponde agradecido a la preferencia que V.S.Y. le haga con dicho nombramiento; cuyo encargo servirá gustoso con el salario de los quinientos ducados annuos con que el Supremo Consejo de Castilla lo tiene dotado, o en los terminos que V.S.Y. tenga por conveniente; pues su principal fin es el de hacer demostrable su aplicacion y deseo de servirle, assi en sus asuntos particulares como en los que sean de beneficio de la causa publica; y para conseguirlo todo = Supp ${ }^{c a}$. rendidamente a V.S.Y. que en vista de quanto deja expuesto se digne conferirle el citado nombramiento de su Arquitecto, o Mtro. Mayor de obras; como assi lo espera de su benignidad y grandeza = Sevilla, y Abril 3 de 1786 = Fernando Rosales".

3. Fernando Rosales solicita licencia para ejecutar obras en la c/ Bayona (actual Federico Sánchez Bedoya, 5). Sevilla, 20.Ago.1804. Documento inédito

AHMS, C. A. Abecedario de calles, Expedientes de licencias de obras, Años 1789-1877. Calle Bayona, Expte. 2/1804, Microfilm 470

\section{Exmo. Señor}

Fernando Rosales, Maestro de Obras de esta Ciudad con la devida atencion a V.E, Dice: que en casa que esta reedificando en Calle Baiona es forzoso hacer de nuevo su fachada con arreglo a el dizeño que presenta con la devida solemnidad cuia casa pertenece a (en blanco) Maestro de coches que la esta viviendo, sin que sea necesario 
sacar de cimientos la referida pared por estar suficiente y robustos y a fin de que se execute dicha obra segun corresponde y sin causar perjuicio:

Supp $^{c a}$ a V.E. se sirva conceder su licencia en la forma ordinaria Que en ello recevira merced

Fernando de Rosales

\title{
4. Fernando Rosales y otros tres maestros reconocen y aprecian una casa y solar contiguo en la calle de los tiros. Sevilla, 6.Mar.1815. Documento inédito
}

\author{
AHPS, FPN, Of. 15, Año 1815, F. 222r-241r, Sign. 9604
}

Decimos Fernando Rosales Maestro de Arvañileria y Fran ${ }^{c o}$ de Osorno que lo es de Carpinteria los dos nombrados por $D^{a}$ Maria Josefa Moron y Santiago de la Llosa Maestro tambien de Arvañileria y Agustin Truxillo que lo es de Carpinteria nombrados por $D^{n}$ Juan Gonzales y todos quatro Vesinos de esta Ciudad pasamos a la Calle de los tiros Collasion de $S^{n}$ Lorenzo para rreconoser y apresiar una Casa y un Solar contiguo en venta rreal y estando en ella todos quatros Juntos de Conformidad y buena armonia la rreconosimos por lo ynterior y esterior y la hallamos Sellada con el $N^{o} 9$ del Gobierno lindando por su derecha Con el dicho Solar del mismo Dueño y por su disquierda con casas de los erederos de $D^{n}$ Tomas Sanchez por su Cavesero y un Costado de derecho Con otras Casas de $D^{n}$ Antonio fernandes Canonigo de Nro. Sor el Salbador, y abiendola medido Su Area Superfisial le Contamos tener o Conponerse de 249 baras quadradas yncluso los muros de Paredes que Corresponde a sus medianerias, y Se Conpone la rreferida Casa de un Saguan y en lo ynterior un patio dos Corredores dos Salas y entresala en el Cuerpo de Calle y en lo ynterior tres Salas un Comedor Cosina Poso y Patinillo todo Sensillo y una escalera que da uso a lo alto que se conpone de un Corredor Serrado una Sala y alcova y Cosina y en lo rrestante un mirador sovre la Sala que mira a la Calle, y abiendo medido todas sus paredes Solerias texados enmaderados Puertas Ventanas rrejas Varandas y abiendo echo la quenta partes y pormenor de Cada espesie Segun el Ser y estado que en el dia Se halla Desimos todos quatro de Conformidad vale la espresada Casa en el Dia bendida en benta rreal la Cantidad de beinte y un mil y quatrosientos de lo que se debe rrebajar el tributo o grabamen que sobre si tenga, Asimismo pasamos al dicho Solar Contiguo y abiendolo rreconosido lo allamos Sercado en toda Su linea Como asimismo la pared de la Calle asta el arto de Siete baras sin ynclusion de su simientos Lindando por su derecha Con Casas de las Monjas de Pasion por su disquierda Con la rreferida Casa antedicha de Da Maria Moron por su Cavesero Con otras Casas del Monasterio de Cartuxa y abiendola medido Su Area Superfisial Con la bara rreferida Se Conpone de Dosientas nobenta y siete baras quadradas Con la ynclusion de Sus medianerias y abiendole dado el balor que le corresponde Segun su estado y ser en que en el Dia se halla Como asimismo una Cavallerisa que ase frente a su entrada Con un doblado que la Cuvre Con Su pozo y Corral y un Colgiso que tiene a el Costado y abiendo echo 
la quenta por partes y por menor de Conformidad desimos valer nueve mil siento y sinquenta rreales de Vellon que unido el anterior apresio de 21400 rreales suman la cantidad de 30550 de los quales se debe rrebaxar las pensiones que sobre si tenga, todo lo qual emos echo bien y fielmente segun nro lear Saber y entender lo que en forma Juramos este espresado Dia mes y año

Fernando de Rosales

Santiago de la Llosa
Fran $^{\text {co Osorno }}$

Agustin Truxillo 